\title{
Piotr Złotkowski
}

Uniwersytet Marii Curie-Skłodowskiej w Lublinie (Polska)

Maria Curie-Skłodowska University in Lublin (Poland)

E-mail: pzlotko@poczta.umcs.lublin.pl

\section{Nazwiska, przezwiska i przydomki młynarzy \\ i mieszkańców osad młyńskich dawnego starostwa brańskiego na Podlasiu w XVI-XIX wieku}

Прозвішчы і мянушкі млынароў і жыхароў млынарскіх паселішчаў даўняга бранскага стараства на Падляшшы у XVI-XIX cm.

Surnames, nicknames and sobriquets of millers and inhabitants of mill villages of the former Brańsk starosty in the Podlasie region in the 16th-19th centuries

elem niniejszego artykułu jest zarysowanie najważniejszych tendencji, które do-
prowadziły do ukształtowania się systemu nazwisk wśród młynarzy zamiesz-
kujących dawne starostwo brańskie. Teren ów, co znajduje odzwierciedlenie
w tekstach opracowań onomastycznych, jest niezwykle interesujący dla potencjalnych
badaczy i inspirujący do prowadzenia pogłębionych studiów onomastyczno-histo-
rycznych. Nazewnictwo osobowe tego obszaru jest systematycznie badane przez na-
ukowców z różnych ośrodków akademickich ${ }^{1}$. Brańsk i okolice również wzbudzały
zainteresowanie badaczy antroponimii ${ }^{2}$. Co zatem stanowi o atrakcyjności badań ono-

Zob. Bibliografia

2 Z. Abramowicz, Antroponimia Brańska w XVII wieku w kontekście ksztattowania się nazwiska na Podlasiu, [w:] Metodologia badań onomastycznych, Olsztyn: Ośrodek Badań Naukowych im. Wojciecha Kętrzyńskiego, 2003, s. 139-149; L. Dacewicz, Nazewnictwo kobiet w starostwie brańskim, „Białostocczyzna” 1994, 4, s. 69-71, Białostockie Towarzystwo Naukowe, Towarzystwo Przyjaciół Brańska; B. Tichoniuk, Imiennictwo osobowe Brańska w XVI wieku, [w:] Nazwy wtasne a wyrazy pospolite w języku i tekście, Opole: Wyższa Szkoła Pedagogiczma im. Powstańców Sląskich, s. 235-238; P. Złotkowski, Strukturno-semanticzeskij analiz polsko-wostocznostawianskich gibridnych familij żytielej Branskogo starostva w XVI-XVIII ww., [w:] Onomastika Povolzja, Moskwa: Instytut Etnologii i Antropologii RAN, 2001, s. 80-86. 
mastycznch Podlasia? Niewątpliwie ma na to wpływ zróżnicowanie etniczno-kulturowe i wyznaniowe, a w przeszłości również społeczne ${ }^{3}$.

Brańsk, jedno z ważniejszych miast ziemi bielskiej, siedziba sądów grodzkich i ziemskich oraz miejsce odbywania sejmików, a także ośrodek administracji dóbr królewskich, leżał na styku terenów zamieszkałych przez przedstawicieli dwóch żywiołów osadniczych - potomków dawnych Mazowszan i Rusinów wołyńskich. Z zachodu ukształtował się więc zwarty kompleks osadnictwa zachodniosłowiańskiego (potomków szlachty i chłopów), na wschodzie powstało wiele osad z ludnością pochodzenia wschodniosłowiańskiego (o genezie bojarskiej i chłopskiej) ${ }^{4}$.

Nie ulega najmniejszej wątpliwości, że młynarze stanowili najbogatszą, dobrze uposażoną w ziemię, najbardziej uprzywilejowaną i wpływową część ludności chłopskiej. Posiadana przez nich ziemia nie była ich własnością, należała do króla, lecz mogli oni nią swobodnie obracać (sprzedawać, darować) i dziedziczyć. Młyny znajdujące się w starostwie brańskim leżały nad rzekami Nurcem, Bronką, Lichczą, Czarną. Z czasem dookoła młynów wytwarzały się osady młyńskie, zamieszkałe często przez potomków pierwszego osadnika. $Z$ reguły należały do nich grunty leżące w pobliżu młyna: w dużej części łąki, pastwiska, podmokłe zarośla, natomiast znacznie mniej było tam gruntów ornych. Młynarze, dzięki sporej powierzchni posiadanych łąk i pastwisk, a także dysponując różnego rodzaju odpadami z przerobu zboża, potrafili utrzymywać dość duży inwentarz żywy. Gospodarstwa młyńskie miały o wiele bardziej hodowlany charakter niż chłopskie, mieszczańskie czy też folwarczne. Bardzo często przy młynach istniały również stawy, w których młynarze prowadzili gospodarkę rybną. Budynki gospodarskie, oprócz oczywiście samego młyna, były też znacznie obszerniejsze i solidniejsze niż w zwykłym gospodarstwie chłopskim. Niekiedy można by je porównać do niewielkich folwarków szlacheckich ${ }^{5}$. Omawiany model osadnictwa przypomina nieco osiedla, licznej na tym terenie, drobnej szlachty. Osady młyńskie bardzo często miały nazwy o charakterze rodowym. W starostwie brańskim były to następujące osady: Abramiki, Burkaty, Jarmarkowszczyzna, Otapy, Pace, Puchacze, Solniki, Torule, Wojtki i nieistniejące już punkty osadnicze: Mielechy, Nełchy, Onacki, Wilginie, Wysockie, Żegunie oraz nieistniejące młyny Kumat, a także Krupki.

3 Z. Abramowicz, L. Citko, L. Dacewicz, Stownik historycznych nazw osobowych Białostocczyzny $(X V-X V I I$ w.), t. 1-2, Białystok: Instytut Filologii Wschodniosłowiańskiej Uniwersytetu w Białymstoku, 1997, s. 3; M. Sajewicz, O polsko-ukraińskiej granicy językowej na Biatostocczyźnie, „Rozprawy Slawistyczne", t. 12, red. F. Czyżewski, M. Łesiów, Lublin: Wydawnictwo Uniwersytetu Marii Curie-Skłodowskiej, 1997, s. 91-107; M. Sajewicz, Nazwiska patronimiczne z formantem -uk w powiecie hajnowskim na Białostocczyźnie na tle ogólnopolskim, Lublin: Wydawnictwo Uniwersytetu Marii Curie-Skłodowskiej, 2013, s. 13-22; B. Tichoniuk, Imiona i ich formy na pograniczu polsko-białoruskim od XVI wieku do roku 1839, Zielona Góra: Wydawnictwo Wyższej Szkoły Pedagogicznej im. Tadeusza Kotarbińskiego, 2000, s. 60.

4 Por. J. Wiśniewski, Osadnictwo wschodniej Białostocczyzny - geneza, rozwój oraz zróżnicowanie i przemiany etniczne, „Acta-Baltico-Slavica”, R. 11, 1977, s. 69-74, Zakład Narodowy im. Ossolińskich.

5 B. Baranowski, Polskie młynarstwo, Wrocław: Zakład Narodowy im. Ossolińskich, 1977, s. 62-63. 
Należy podkreślić, że młynarze byli raczej zamkniętą grupą, którą w części zasilali przybysze z sąsiadujących z osadami młyńskimi wsi chłopskich starostwa brańskiego, m.in. z Oleksina, Chojewa, Holonek i in. Byli to zazwyczaj bogaci chłopi, często sołtysi oraz tzw. wybrańcy, mający obowiązek służby w piechocie wybranieckiej. Możliwy był jednak awans niektórych, bardziej ambitnych przedstawicieli tej grupy do szeregów mieszczaństwa, a nawet szlachty. Należy zauważyć, że w związku ze stopniowym rozradzaniem się rodów młynarskich następowało ich ubożenie, przyczyniające się do zmniejszenia ich roli gospodarczej i społecznej. Proces ten rozpoczął się już w XVIII wieku i pogłębiał w następnym stuleciu.

Do badań nad nazewnictwem młynarzy starostwa brańskiego wykorzystano trzy rodzaje źródeł historycznych: metrykalne, fiskalne i sądowe. Materiał źródłowy wyekscerpowano więc z XVII- i XVIII-wiecznych ksiąg metrykalnych parafii Brańsk, Boćki, Dołubowo, Łubin Kościelny, XIX-wiecznego spisu parafialnego parafii Brańsk, datowanych na XVII-XVIII wiek podlaskich rejestrów podatkowych oraz ksiąg godzkich brańskich, pochodzących z okresu od poł. XVI do końca XVII wieku. Dodatkowo posłużono się danymi z XVI-wiecznych źródeł drukowanych: inwentarza starostwa brańskiego z 1558 roku oraz pochodzącego z lat 1560-1563 rejestru pomiary włócznej starostwa brańskiego ${ }^{6}$ (zob. Źródła). Wydaje się, że wymieniona baza źródłowa pozwala na ukazanie choćby w zarysie procesu kształtowania się nazwisk młynarzy dawnego starostwa brańskiego. Każdy rodzaj źródeł cechuje swoisty sposób identyfikacji antroponimicznej występujących w nich osób. Najbardziej dokładny sposób identyfikacji onomastycznej stosowany był w źródłach sądowych, nieco mniej skrupulatny - w księgach metrykalnych, wiele zaś do życzenia, jeśli chodzi o ilość i jakość podanych informacji, pozostawiają źródła fiskalne. Wykorzystanie tylko jednego rodzaju materiałów źródłowych, co niestety praktykowane jest $\mathrm{w}$ niektórych pracach onomastycznych, daje niepełny obraz systemu nazewniczego, a niekiedy może nawet zniekształcić wyniki badań. Dopiero kompleksowe wykorzystanie wszystkich dostępnych rodzajów źródeł pozwala na osiągnięcie satysfakcjonujących rezultatów badań antroponimicznych.

Dla potrzeb niniejszego opracowania zbadano nazwy osobowe z okresu od poł. XVI do pocz. XIX wieku, co pozwoliło na uchwycenie procesu kształtowania się nazwisk w osadach młyńskich.

Przeprowadzona analiza struktury nazwisk mieszkańców osad młyńskich dawnego starostwa brańskiego ujawniła następujące modele słowotwórcze:

1. Struktury niederywowane:

- odimienne: Abraham, Bogusz, Burta, Burkat, Chwanito, Florek/Frolek, Jarosz, Juc, Kumat, Mackiel, Matuch, Michel, Mielech/Mieloch, Milej, Mojsa, Momot, Odachim, Onacko, Owsiej, Pac, Panas, Piotraszko, Radziwon, Sawka/Sawko, Sierko, Stasitko, Stasileńki, Szczęsny, Waloch, Wawryn, Wietoszkal Wietuszka, Zachar, Żoch;

6 Zob. Źródła. 
- odapelatywne: Acz, Buhaj, Bruzgiel, Caban, Derehajto, Dermiaha, Duma, Dziki, Gr(z)ebien, Grela, Kalina, Kisiel, Koniuch, Koniuszek, Korobus, Kowal, Koziet/Koziol, Kożuch, Krupka/Krupko, Kuśnierz, Marmol, (Me)tropolit, Moczula, Mucha, Nieroda, Pikuła, Przystupa, Poletyło, Pop, Puchacz, Reczka, Rokita, Solnik, S(z)urma, Szlachetka, Szpak, Święty, Torula/Turula, Tur, Wilginia, Wilkin, Woronka, Wróbel, Żegun, Żuk;

- odapelatywne lub odimienne: Jawor;

- odetnonimiczne: Moskal, Litwin, Mazur.

2. Struktury derywowane:

a) z formantem -ski, -(ow)ski, -(ew)ski, -cki: Brzozowski, Burtaski, Czarniawski, Dabrowski, Dębowski, Dołobowski, Domański, Dworecki, Gawęcki, Gliński, Gudowski, Jakubowski, Jankowski, Kadtubowski, Kalinowski, Kamiński, Kozłowski, Kraszewski/Kraszowski, Kunicki, Lewkowski, Łubiński, Malinowski, Maliński, Materski, Markowski, (N)iwiński, Olędzki, Osmolski, Pieczeński, Piotrowski, Puchalski, Rogucki, Romanowski, Rutkowski, Ryszkowski, Sawicki, Siedlecki, Sieklucki, Sielicki, Skotnicki, Sokołowski, Szadkowski, Szepietowski, Szpakowski, Śliwiński, Śliwowski, Śpieszyński, Totwiński, Tuszewicki, Wilczewski, Wiśniewski, Wojtkowski, Wronowski, Wróblewski, Wysocki, Zalewski/Zaliwski, Zieleniewski, Zielenkowski, Żochowski, Żukowski;

b) z formantem $-u k,-c z(u k)$ :

- odimienne: Aleksandruk, Barttomiejczuk, Bartoszuk, Chwiedorczuk, Danilczuk, Eliasiuk, Filuk, Florczuk, Francuk/Frączuk, Grzesiuk, Grzeszczotczuk, Hrehorczuk, Hryniuk, Iwaniuk, Jacczuk, Janiuk, Joziuk, Jozwiczuk, Juciuk, Koczuk, Kostenczuk, Łukiańczuk, Jachoniuk, Jarosz(cz)uk, Kosczuk, Marciniuk, Matysiuk/Matyszuk, Michalczuk, Mielczuk, Mieleszuk, Mikołajczuk, Milejczuk/ Meleczuk, Momociuk, Olesiejczuk, Otdachimczuk/Ołdakimczuk, Owsieniuk/ Owsiejuk, Panasiuk, Pawluczuk, Pawluk, Petroszuk, Radywonczuk, Rehorczuk, Romanczuk, Sidorczuk, S(i)emeniuk, Stasitczuk, Stasiuk, Szancuk, Szczepaniuk, Szczęśniuk, Szymczuk, Tarasiuk, Tomczuk, Tymosiuk, Wawryniuk/Wawr(z)eniuk, Zacharczuk, Zygmonciuk, Żoszuk;

- odapelatywne: Cabanczuk, Cabaniuk, Caruk, Czoł(c)zuk, Czerczuk, Dumiuk, Grelczuk, Grzebieniuk, Haciuk, Koniuszuk, Kozluk, Noroziuk, Szpaczuk, Ślusarczuk, Trelczuk, Tropoliciuk, Worobiuk;

- odapelatywne, odimienne lub odetniczne: Laszuk;

c) z formantem $-a k$ :

- odimienne: Bohdziak, Kuźmiak, Matysiak, Marciniak, Mieleszak, Pawlak;

d) z formantem $-i k,-y k,-(c z) y k$ :

- odimienne: Abra(ha)mik, Augustynik, Barttomiejczyk, Bartosik/Bartoszyk, Chumczyk, Chwanilik/Fanilik, Florczyk, Hermanik, Iwanik, Jakubik, Jozwik, Juchnik, Juc(z)yk/Judczyk, Karolasik, Kosciuczyk, Lewonik, Maksimik, Marcinik, Matysik, Ondryk, Radionik, Radywonik, Semenik, Stachnik, Stasitczyk, Szczepanik, Ustianik, Wasilczyk, Wasiuczyk, Zacharczyk; 
- odapelatywne: Czotzyk, Dumik, Korpaczyk, Latinik, Moczulik, Otapik, Puchaczyk, Puscik/ Puszczyk, Skłodzik, Solniczyk, Szlachatczyk/Szlachecczyk, Ślusarczyk, Trzpetunik, Tur(z)yk, Wilkinik;

- odmiejscowe: Dolobowczyk;

- odetniczne: Mazurczyk;

e) z formantem -(ow)icz, -(ew)icz:

- odimienne: Burkatowicz, Chwiedorowicz, Chylewic, Decewicz, Fanelowicz, Jaczkiewicz, Jakoniewicz/Jakowienicz, Malosicz, Markowicz, Miloicz, Miskowicz, Mochnowicz, Nestorowicz, Nietchowic, Onackowicz, Paczewic(z), Pawtowicz, Pieczewicz, Romanowicz, Tysowicz, Wasiukowicz, Zacharowicz;

- odimienne lub odetnonimiczne: Serwinowic;

- odapelatywne: Aczewicz, Bockowicz, Kozlowicz, Puchaczowic, Pusczyc, Rojewicz, Turulowic, Wilkinowicz, Zajkoic, Żegunicz;

- odapelatywne lub odimienne: Leskowicz;

- odmiejscowe: Tuszewicz;

f) z formantem -enie:

- odimienne: Abrahamowienie, Jackowienie, Jankowienie, Markowienie, Tonaczkowienie.

3. Composita: Pokinbaba.

4. Niejasne (ze zniekształconym zapisem, utrudniającym interpretację językową):

Chraosik, Otap(a), Otapiuk, Surojeskowicz, Walkołoch.

$\mathrm{Z}$ przytoczonych danych wynika, że nazwiska w osadach młyńskich tworzone były od podstaw apelatywnych i imiennych o genezie zarówno zachodnio-, jak i wschodniosłowiańskiej. Analiza owych antroponimów utwierdza nas w przekonaniu, że są to struktury typowe dla pogranicza, a szczególnie dla obszaru ścisłego styku obu etnosów. Wczesne struktury nazewnicze młynarzy na badanym terenie zawierały znaczny odsetek derywatów nazwiskowych na -(ow)icz, -(ew)icz, późniejsze derywowane były przeważnie przy pomocy formantów $-i k,-y k,-(c z) y k$, oraz $-a k$ i $-u k$. Na szczególną uwagę zasługuje znaczna ilość formacji typu nazwiskowego z zakończeniem -ski, -(ow) $s k i$, -(ew)ski, -cki, co, biorąc pod uwagę tutejszą specyfikę nazewniczą, nie powinno specjalnie dziwić. Najprawdopodobniej oddziaływał w tym przypadku model wzorcowego nazwiska szlacheckiego ${ }^{7}$. Osady młyńskie wraz z całym starostwem brańskim sąsiadowały z rozległym obszarem osadnictwa drobnoszlacheckiego i bojarskiego, co niewątpliwie miało wpływ na przenikanie wzorców nazewniczych. Wiele nazwisk ma w podstawie nazwy miejscowe sąsiednich wsi szlacheckich, np.: Jakubowski (od n.m. Jakubowskie), Markowski (od n.m. Markowo), Osmolski (od n.m. Osmola), Puchalski (od n.m.Puchaty), Sieklucki (od n.m. Siekluki) i in. Wiele wskazuje na to, że nazwiska te zostały przyjęte przez naśladownictwo wyżej wspomnianego wzorca. Niewykluczone jednak, że mogą to być antroponimy zachowane przez zdeklasowanych przedstawi-

7 Por. L. Dacewicz, Historia nazwisk na kresach pótnocno-wschodnich Rzeczpospolitej (XVI-XVIII w.), Białystok: Wydawnictwo Uniwersytetu w Białymstoku, 2014, s. 134-137. 
cieli stanu szlacheckiego, którzy mogli osiąść w osadach młyńskich w poszukiwaniu lepszych perspektyw życiowych. Należy pamiętać, że szlachta mogła dzierżawić młyny lub części osad młyńskich, co znajduje poświadczenie w źródłach.

$\mathrm{W}$ badanym materiale odnotowano znaczny procent nazwisk $\mathrm{z}$ formantem $-u k$, $-c z(u k)$. Należy stwierdzić, że tego typu formacje są elementem miejscowej specyfiki nazewniczej. Antroponimy te zaczynają pojawiać się w II poł. XVII wieku, a szczególne ich nasilenie można zaobserwować w źródłach z XVIII wieku . O ile struktury typu Sidorczuk, Romanczuk charakterystyczne są raczej dla północnej i wschodniej części starostwa brańskiego, o tyle takie antroponimy, jak Bartoszuk, Janiuk, Szymczuk, będące $\mathrm{w}$ istocie formacjami hybrydalnymi, częściej odnotowuje się we wsiach po zachodniej stronie Nurca, a więc w południowo-wschodniej części tegoż starostwa. Tego typu formacje hybrydalne są charakterystyczne dla obszarów bezpośredniego styku etnosów i stamtąd rozprzestrzeniały się dalej na zachód ${ }^{9}$. Proces ten mógł się rozpocząc już w XVII wieku i trwać poprzez XVIII i XIX wiek do czasów nam współczesnych.

Proces kształtowania się nazwisk młynarzy był dość długi. Zakończył się dopiero w XIX wieku. Wtedy właśnie wykształciły się nazwiska w dzisiejszym rozumieniu tego terminu jako struktury dziedziczne i ustabilizowane formalnie. Używane do tego czasu przednazwiskowe nazwy osobowe miały nieustabilizowany charakter, przypominając pod tym względem dzisiejsze przezwiska i przydomki. System ten charakteryzował się otwartością i bogactwem form ${ }^{10}$. Istotną kwestią, którą należy brać pod uwagę $\mathrm{w}$ badaniach nad antroponimią historyczną społeczności lokalnych, jest kwestia ciągłości osadnictwa rodowego i rodzinnego. Do jej przerwania w osadach młyńskich mogło dojść w wyniku zmian i przekształceń własnościowych w obrębie całej lub części wsi, naturalnego wymierania rodów, związanego z brakiem męskich potomków, migracji oraz wojen lub klęsk żywiołowych. Dodatkową komplikacją, utrudniającą badania, jest nie w pełni zachowana baza źródłowa. Trzeba jednak przyznać, że zastosowanie metody kompleksowej analizy antroponimicznej, z wykorzystaniem wspomnianych wcześniej trzech typów źródeł, pozwala na odtworzenie w miarę spójnego obrazu przekształceń i zmian nazewniczych.

Dla zobrazowania procesu kształtowania się struktur proprialnych osad młyńskich dawnego starostwa brańskiego pomocne są wprowadzone ostatnio do literatury onomastycznej pojęcia sufiksalnych derywatów nazwiskowych oraz nazwisk koreferencyjnych, tj. antroponimów o odrębnych formantach identyfikujących tę samą osobę ${ }^{11}$.

8 Ibid., s. 107-109.

9 P. Złotkowski, Strukturno-semanticzeskij analiz polsko-wostocznosławianskich gibridnych familij żytielej Branskogo starostva w XVI-XVIII w., [w:] Onomastika Povolżja, Moskwa: Instytut Etnologii i Antropologii RAN, 2001, s. 80-86.

10 B. Tichoniuk, Antroponimia południowej Białostocczyzny, Opole: Wyższa Szkoła Pedagogiczna im. Powstańców Sląskich, 1988, s. 111-112; L. Dacewicz, Nazewnictwo kobiet w starostwie brańskim, „Białostocczyzna” 1994, nr 4, s. 69-71, Białostockie Towarzystwo Naukowe, Towarzystwo Przyjaciół Brańska, s. 71.

11 H. Górny, O strukturach proprialnych i procesach nazwotwórczych - od ujęć dawniejszych po najnowsze teorie, „Onomastica”, R. 58, 2014, Zakład Narodowy im. Ossolińskich, s. 94-96. 
W analizowanym materiale nazewniczym udało się wyodrębnić znaczną liczbę formacji zróżnicowanych chronologicznie, określających tę samą osobę. Część z nich stanowią nazwiska o różnych podstawach semantycznych, część zaś nazwiska koreferencyjne. Wśród tych struktur dominują zestawienia dwuelementowe, znacznie mniej jest zestawień trzyelementowych i czteroelementowych. Odwzorowują one przebieg formowania się nazwisk. Oto przykłady niektórych z nich:

\section{Zestawienia dwuelementowe:}

Stefan Osmolski Solnik: Honesto Stephano olim Alberti Solnik 1670, Honesto Stephano Osmolski 1672

Józef Brzozowski Wawreniuk: Honestorum Josephi Waureniuk et Mariannae 1731, Lab: Josephi Brzozowski et Mariannae 1734

Krzysztof Burta Rogucki: Laboriosor[um] Christophori Burta et Christinae 1760, Cristofori Rogucki et Cristinae 1765.

\section{Zestawienia trzyelementowe:}

Michał Czołzuk Kamiński Koniuch: Laboriosor[um] Michaelis Kamienski et Catharinae 1726, Michaelis Kamienski dicti Czolzuk et Catharinae 1729, LL. Michaelis Koniuch et Catharinae 1730

Tomasz Puchalski Żoch Żochowski: Tomae et Ludvicae Puchalskich 1770, Honesti Thoma Zoch et Ludouika 1774, Famator[um] Thomae Zochoski et Ludovicae 1777

Józef Kamiński Matysiak Matysiuk: Honesto Josepho Matysiak legitima eius Coniux Apolonia Tomczanka 1800, Josepho Kamienski legitima eius Coniux Appolionia Szymczanka 1802, Josepho

Matisiuk legitima eius Coniux Apollonia Szymczukowa 1805.

\section{Zestawienia czteroelementowe:}

Jakub Iwaniuk Janiuk Siedlecki Żegunia: Jacobi Żegunia et Clarae 1761, H. Jakobi et Clarae Siedleckich 1762, Jacobi et Clarae Janiukow 1765, Jacobi et Clarae Ivaniukow 1770.

\section{Zestawienia pięcioelementowe:}

Jan Brzozoski Pawlak Stasiłczuk Stasiłko Zaliwski: Laboriosor[um] Joannis Brzecoski et Cristinae 1697, Laboriosor[um] Joannis Pawlak Stasilko et Chrystinae 1700, Honestor[um] Joannis Stasilczuk et Christinae 1703, Joannis Zalewski et Christinae 1722, honesti Joannis Zaliwski et Christinae 1726.

Jeden z członów zestawienia antroponimicznego z czasem ustalał się jako dziedziczny, wypierając pozostałe. Proces ten mógł trwać od kilkunastu, kilkudziesięciu 
do nawet kilkuset lat. Obejmował więc okres od jednego do kilku pokoleń. Nic więc dziwnego, że zaczątki niektórych dziedzicznych formacji antroponimicznych sięgają w badanym środowisku nawet XVI wieku, np. Tuszewicki, Żegunia ${ }^{12}$. Są to jednak formacje stosunkowo nieliczne, podobne pod pewnymi względami do pierwotnych rodowych antroponimów, a późniejszych nazwisk miejscowej drobnej szlachty.

Wydaje się, że okresem decydującym dla kształtowania się nazwisk mieszkańców osad młyńskich starostwa brańskiego był XVIII wiek i I poł. XIX wieku. W tym właśnie czasie ustabilizowało się i ostatecznie utrwaliło wiele istniejących do dnia dzisiejszego antroponimów.

Poniżej zamieszczono słownik antroponimów (nazwisk, przezwisk i przydomków) młynarzy i mieszkańców osad młyńskich dawnego starostwa brańskiego w XVI-XIX wieku. Zawiera wyekscerpowane ze źródeł historycznych formy męskie antroponimów w N.sg. Zestawienie nie obejmuje dzierżawców oraz właścicieli młynów pochodzenia szlacheckiego. Dodatkowo podano chronologię zapisu, skrót nazwy źródła oraz skrót nazwy miejscowości, w której odnotowano onim.

\section{Słownik antroponimów}

Abraham: Młynarza Abrahama Mikity z Szapkow 1638 Ks. Ref. 58, k. 116 v.

Abra(ha)mik: Mikita Abramik 1651 M 1708-1-141, k. 637 PU; Fiedor Abramik Mlynarz, Pawet Abramik Mtynarz 1667 AR XXV 362a, k. 9 v. PU; Honestus Roman olim Pauli Abrahamik 1688 M 1708-1-188, k. 545 PU; Honesto Petro Jabramik 1690 M 1708-1-57, k. 263 v. PU; Stefan Abramik żona 1692 KGB 52, k. 202 PU

Abrahamowienie: Honestus Georgius Abrahamowienie filius olim Mikita 1665 M 1708-1-158, k. 233 v. PU

Acz: HH. Joannis et Ripinae Aczow 1769 Ł I/B/4 PU

Aczewicz: Joannes Aczewicz 1731 Ł I/B/2 PU

Aleksandruk: Jasko Alexandruk przeł. XVIII/XIX w. KWD 692 PU

Augustynik: Honesto Felici Augustynik 1632 RA Enskilda 8636, k. 139v-140v.

Bartlomiejczuk: Laurentij Baltromieyczuk $1707 \mathrm{Br} \mathrm{I/B/2} \mathrm{BU}$

Bartlomiejczyk: Wawryn Barttomieyczyk z synami dwiema 1716 KGB 44, k. 377 v. BU

Bartosik: Woyciech y Grzegorz Bartosikowie Bracia 1661-1664 AR XXV 361 WO

Bartoszuk: Malusz Bartoszuk przel. XVIII/XIX w. KWD 692 BU

Bockowicz: Honestum Onaczko Bockowicz 1599 MK143, k. 186 ON

Bogusz: Stanislaw Bogus 1681 M 1802-1-1, k. 189 v. OT

Bohdziak: Alberti Bohdziak $1647 \mathrm{Br} \mathrm{I} / \mathrm{B} / 1 \mathrm{BU}$

Bruzgiel: Stanislai Bruzgiel 1651 M 1708-1-141, k. 464 v. BU

Brzozowski: Honestor Joannis Brzozowski et Sophiae 17291734 Br I/B/2 BU

12 P. Złotkowski, O pochodzeniu nazwy uroczyska Kumat pod Brańskiem. Czyżby koniec legendy?, „Studia Białorutenistyczne”, t. 8, red. M. Korzeniowski, S. Kawalou, M. Sajewicz, Lublin: Wydawnictwo Uniwersytetu Marii Curie-Skłodowskiej, 2014, s. 240-242. 
Lab: Josephi Brzozowski 1734 Br I/B/2 BU; Jan po Kazimierzu Brzozowski 1846 Br III/S/1 BU Buhaj: Jacobum Buhay 1678 Br I/B/1 WY

Burkat: Jana Burkata 1563 PKGE II 409 BU; Thomasz Burkat 1637 Ks. Ref. 58, k. 24 BU; Honestos Simonem Joannem Nicolaum et Albertum Burkatom 1651 M 1708-1-141, k. 835835 v. BU; R. Woyciech Burkat z Szymonem synem 1692 KGB 52, k. 187 v. WI; Nicolai Burka, Michat Burka przeł. XVIII/XIX w. KWD 692 BU

Burkat Momociuk: Szymko Borkacz Momosiuk 1681 M 1708-1-176, k. 237 BU

Burkatowicz: Janko z Lymanem Burkatowiczy, Szymon Burkatowicz, Janko z Miskiem Burkatowiczy 1558 AVAK IV 27 BU

Burta: Francisco Burta 1802 D I/B/1a WI

Burtaski: Franz Burtaski przeł. XVIII/XIX w. KWD 692 WI

Caban: Lab: Adalberti Czaban $1703 \mathrm{Br}$ I/B/2a JA

Caban Zacharczuk: Albertum Czaban Zacharczuk $1713 \mathrm{Br}$ I/B/2a JA

Cabanczuk: Honesti Alberti Czabanczuk $1687 \mathrm{Br} \mathrm{I} / \mathrm{B} / 1 \mathrm{JA}$

Cabaniuk: Woytko Czabunik z żonq 1692 KGB 52, k. 198 v. JA; Laboriosi Alberti Zabaniuk $1700 \mathrm{Br} \mathrm{I} / \mathrm{B} / 1 \mathrm{JA}$

Caruk: Laboriosor [um] Chwedori Czaruk et Otdotha $1731 \mathrm{\iota} \mathrm{I/B/2} \mathrm{AB}$

Chraosik: Simonis Chraosik 1689 Bk I/B/1b SO

Chumczyk: Michatko Chumczyk 1692 KGB 52, k. 198 v. JA

Chwanilik/Fanilik: Honesti Nicolai Familik Molendinatoris 1650 M 1708-1-141, k. 439 v. BU; Laboriosi Martini Phanilik 1665 Br I/B/1 BU, Laboriosi Martini Fanilik $1667 \mathrm{Br}$ I/B/1 BU; Laboriosi Martini Chwanilik 1671 Br I/B/1 BU; Honesto Alberto filio Nicolai Fanilik 1676 M 1708-1-172, k. 111 v. WI

Chwanito: Marcin Chwanito 1667 AR XXV 362a, k. 5 BU; Laboriosi Mathiae Chwanito Molendinator $1678 \mathrm{Br} \mathrm{I} / \mathrm{B} / 1 \mathrm{BU}$; Josephi Chwanyto et Margaritta $1701 \mathrm{Br} \mathrm{I} / \mathrm{B} / 1 \mathrm{BU}$

Chwiedorczuk: Laboriosorum Gregorij Chwiedorczuk et Mariannae $1725 \mathrm{Br}$ I/B/2a PA

Chwiedorowicz: Gregorii Chwedorowicz et Sophia 1729 Br I/B/2a PA

Chylewic: Honesto Radywon ol Laurenty Chylewic 1663 M 1708-1-43, k. 479 PU

Czarniawski/Czerniawski: Simonis Czerniawski 1767 Ł I/B/4 PU; HH Simonis et Teressiae Czarniawskich 1770 Ł I/B/4 PU; Basil Gerniefs przeł. XVIII/XIX w. KWD 692 JA; Jan Czarniawski 1806 JA; Bazyl Czarniawski 1806 JA; Stanisław po Bazylem Czarniawski, Jan po Piotrze Czarniawski [Umarl] $1846 \mathrm{Br}$ III/S/1 JA

Czaruk: Laboriosor Chwedori Czaruk 1731 Ł I/B/2 AB

Czerczuk: Czerczuk $1672 \mathrm{Br}$ I/B/1 WY

Czol(c)zuk: Honestus Mathias Czolzuk 1685 M 1708-1-182, k. 402 v. PA; Sidor Czolzuk z żonq 1692 KGB 52, k. 199 PA; laboriosi Simonis Czolzuk 1699 Br I/B/1 PA; Marcin Czołczuk $z$ żonq 1716 KGB 44, k. 379 PA

Czołzyk: Honesto Matochfiey filio Tymos Czolzyk 1661 M 1708-1-153, k. 5 v.- 6 PA; Laboriosi Mathochwiey Czotzyk 1668 Br I/B/1 PA

Danilczuk: Franciszek po Daniele Danilczuk l. 391846 Br III/S/1 PA

Dąbrowski: Famati Laurentii Dambrowski Molendinator 1666 Br I/B/1 OT; Honesto Thomae Dąbrowski olim Laurenty Dąbrowski 1691 M 1708-1-192, k. 192 OT; Petri Dąbrowski $1723 \mathrm{Br} \mathrm{I} / \mathrm{B} / 2 \mathrm{a}$ OT 
Dąbrowski Otapik: honesto Laurentio Dąbrouski Otapik molendinatorio 1683 M 1708-1-52, k. 406 OT; Honesti Petri Otapik Dombrowski et Catharinae $1708 \mathrm{Br}$ I/B/2a OT

Derehajło: Prouid. Joannem Derehaito 1607 M 1708-1-98, k. 260 SO

Dermiaha: Laboriosi Adalberti Dermacha et Mariannae 1761 D I/B/1WO ; Honestoru[m] Perti et Ludovicae Dermahow 1773 D I/B/1WO; Laboriosi Gregorij Dermiaha 1713 Br $\mathrm{I} / \mathrm{B} / 2 \mathrm{BU}$

Dębowski: Laboriosorum Paulus Dębowski et Anastasiae $1701 \mathrm{Br}$ I/B/1 BU

Dołobowczyk: honesto Laurentio Dolobowczyk 1666 M 1708-1-158, k. 636 TO

Dołobowski: Famati Laurentii Dołobowski 1675 M 1708-1-171, k. 317 TO; R. Szczepan Syn Wawrzynca Dołobowskiego y Maryanna corka tegoż 1692 KGB 52, k. 187 v. TO; Laboriosi Stephani Dolobowski $1706 \mathrm{Bk} \mathrm{I} / \mathrm{B} / 2 \mathrm{TO}$

Domański: Pauli Domanski 1794 Ł I/B/5 SO; honesto Paulo Domanski 1799 D/I/B/1a ŻE; honesto Ladislao Domanski 1799 D I/B/1a WO; Ladislao Domanski 1805 D I/B/1a WO; Jakob po Stanistawie Domanski l. 371846 Br III/S/1 ON

Duma: Hrydo Dumma przeł. XVIII/XIX w. KWD 692 BU; Marcin po Krzysztofie Duma l. 58 $1846 \mathrm{Br} \mathrm{III/S} / 1 \mathrm{BU}$

Dumik: Pawet Dumik 1716 KGB 44, k. 377 v. BU; laboriosor Mathaei Dumik et Annae 1714 $\mathrm{Br} \mathrm{I} / \mathrm{B} / 2 \mathrm{BU}$

Dunuk: laboriosi Mathaei Dunuk? 1709 Br I/B/2 BU

Dworecki: Laboriosor Maximi Dworecki et Agathae 1722 Br I/B/2 BU; Laboriosorum Maxini Dworecki et Agathae $1724 \mathrm{Br} \mathrm{I} / \mathrm{B} / 2 \mathrm{BU}$

Dziki: Wawrzyniec Dziki 1661-1664 AR XXV 361 NE; Honestus Laurentius filius olim Mathiae Dziki 1675 M 1708-1-171, k. 302-302 v. NE

Eliasiuk: Mikołay po Szymonie Eliasiuk l. $341846 \mathrm{Br}$ III/S/1 WI

Fanelowicz: Laboriosor Josephi Fanelowicz et Margaritt 1700 Br I/B/1 BU

Faniulczyk: Laboriosi Alberti Faniulczyk $1669 \mathrm{Br}$ I/B/1 BU

Filuk: Honesti Gregorii Phulik 1669 Br I/B/1 PA

Florek/Frolek: Jozwa Frolka synow 21716 KGB 44, k. 379 SO; Matthai Florenc et Catharinae $1725 \mathrm{Bk} \mathrm{I/B} / 3 \mathrm{SO}$

Florczuk: R. Józef Florczuk z żona 1692 KGB 52, k. 187 SO; Filiam laboriosorum Stanislai Florczuk 1743 Bk I/B/3 SO; Stanislai et Kristinae Florczuchow 1779 D I/B/1 SO

Florczyk: Stanislai Florczyk et Catharinae $1740 \mathrm{Bk}$ I/B/3 SO

Francuk/Frączuk: Laboriosi Martini Froncuk 1746 Bk I/B/3 WY; Adalberto Francuk 1803 $\mathrm{D} \mathrm{I} / \mathrm{B} / 1 \mathrm{a} \mathrm{WI}$

Gawęcki: Antoni po Janie Gawęcki $1846 \mathrm{Br}$ III/S/1 ON

Gliński: Honesto Pauli Glinski olim Procopii 1675 M 1708-1-171, k. 317 WI; R. Józef syn Pawła Glinskiego y Dorotha tegoż corka 1692 KGB 52, k. 187 v. WI; Laboriosorum Andreae Glinski et Agnetis 1724 Bk I/B/3 WO

Grela: Jacobi Grella et Mariannae $1713 \mathrm{Br} \mathrm{I} / \mathrm{B} / 2 \mathrm{a} W Y$

Grelczuk: laboriosus Jacobus Grelczuk et Mariannae $1711 \mathrm{Br} \mathrm{I} / \mathrm{B} / 2 \mathrm{a} \mathrm{WY}$

Grzebieniuk: Laboriosi Simonis Grzebieniuk 1679 Br I/B/1 BU

Gr(z)ebień: Honesto Simoni Grebienia 1685 M 1708-1-182, k. 155 BU; R. Symon Grzebien 1692 KGB 52, k. 187 v. BU 
Grzesiuk: Laboriosi Joannis Grzesiuk 1678 Br I/B/1 JA; Honesti Nicolai Grzesiuk 1683 Br $\mathrm{I} / \mathrm{B} / 1 \mathrm{WY}$

Grzeszczotczuk: Grzesczotczuk Bratankow dwa y siostra iego 1716 KGB 44, k. 379 PA

Gudowski: L Stephani Gudowski 1697 Bk I/B/1b TO

Haciuk: Jacobi Haciuk 1751 Ł I/B/2 PU; Gregory et Franciscae Haciukow 1770 Ł I/B/4 PU; Michal Haczucz przeł. XVIII/XIX w. KWD 692 AB; Gregor Haczuk przeł. XVIII/XIX w. KWD 692 PU

Hermanik: Honestus Thomas Hermanik 1662 M 1708-1-153, k. 346 JA

Hrehorczuk: Laboriosi Chwiedor Hrehorczuk 1669 Br I/B/1 TO

Hryniuk: laboriosi Philippi Hryniuk 1717 Br I/B/2a WI

Icyk: Laboriosi Laurentij Jcyk et Anastasiaae Mielianka de Wysockie 1658 Br I/B/1 BU

Iwanik: Honestoru[m] Jacobi et Clarae Ivanikow 1778 D I/B/1 WO

Iwaniuk: Jacobi et Clarae Ivaniukow 1770 D/I/B/1 ŻE

Jacczuk: Lab: Gregory Jaccuk et Marinae $1703 \mathrm{Br}$ I/B/2a NE

Jachoniuk: Joannis Jachoniuk? 1753 I/B/2 PU

Jackowienie: Honestus Chuiedor Jackouienie 1666 M 1708-1-158, k. 636 TO

Jaczkiewicz: honesti Joannis Jaczkiewicz et Constantiae 1722 Bk I/B/2 SO

Jakoniewicz: Fedor Jakoniewicz 1661-1664 AR XXV 361 TO

Jakowienicz: Fiedor Jakowienicz z uczestnikami 1667 AR XXV 362a, k. 5 TO

Jakubik: honesti Martini Jakubik 1688 M 1708-1-188, k.199 SO

Jakubowski: Thomam olim Christophori Jakubowski 1724 Br I/M BU; LL. Thomae Jakubowski et Agathae $1730 \mathrm{Br} \mathrm{I/B} / 2 \mathrm{BU}$

Jakubowski Surma: L Christophori Jakubowski Surma 1705 Br I/B/2 BU

Janiuk: Gregorio Janiuk et Heduigis 1686 Br I/B/1 BU; Jacobi et Clarae Janiukow 1765 D/I/B/1 ŻE

Jankowienie: Honestus Stanislaus Jankowienie 1661 M 1708-1-153, k. 76 v. TO

Jankowski: laboriosi Martini Jankowski et Theodorae 1721 Bk I/B/2 WI; Laboriosor[um] Andreae Jankowski et Theodorae Tuszewicka 1728 Bk I/B/3 ON; H[ones]t[o]ri Gaspari et Joannae Jankowskich 1781 D I/B/1WO; Hon. Bartholomaeo Jankowski 1808 D I/B/1a SO; Burt Miakowski przeł. XVIII/XIX w. KWD 692 SO; Grzegorz po Kacprze Jankowski $1846 \mathrm{Br} \mathrm{III} / \mathrm{S} / 1 \mathrm{SO}$

Jarosz: Alexandri Jarosz 1764 Ł I/B/2 PU; Jaszko Jarosz, Ant Jarosz przeł. XVIII/XIX w. KWD 692 PU

Jaroszczuk: Jan Jaroszczuk zona chora 1692 KGB 52, k. 202 PU

Jaroszuk: Demian Jaroszuk z bratem 1716 KGB 44, k. 378 v. PU; Philippum Jaroszuk 1724 $\mathrm{Br} \mathrm{I} / \mathrm{M} \mathrm{PU}$

Jawor: Leonis Jawor 1767 Ł I/B/4 PU

Joziuk: Famatorum Alexandri Mariannae Joziukow 1768 Ł I/B/4 PU

Jozwiczuk: Alexandri Jozwiczuk 1755 Ł I/B/2 PU

Jozwik: Iwan Jozwik z żoną 1716 KGB 44, k. 378 v. PU

Juc: Joanne Juc $1692 \mathrm{Br} \mathrm{I} / \mathrm{B} / 1 \mathrm{WY}$

Juchnik: R. Kazimierz Juchnik Parobek P. Arwatowicza tegoż dziwka Magdalena y komornik Oldakim 1692 KGB 52, k. 187 v. BU 
Juciuk: Laboriosi Andreae Juciuk 1706 Bk I/B/2 WY

Jucyk Wysocki: honesti Pauli Jucyk Wysocki 1681 M 1708-1-176, k. 237 WY

Ju(d)czyk: Pauli Juczyk 1647 Br I/B/1 WY; Pawet Judczyk 1667 AR XXV 362a, k. 5 WY; R. Andrzey Juczyk z Barbara siostra, R. Jan Juczyk z żona 1692 KGB 52, k. 188 WY

Kadłubowski: Famatorum Laurentii Kadtubowski 1730 Br I/B/2a OT

Kalina: Laboriosi Leszko Kalina 1665 Br I/B/1 WY

Kalinowski: Laboriosi Alexandri Kalinowski 1672 Br I/B/1 WY; Jacobi Kalinowski 1714 Bk I/B/2 SO; Hon. Mathao Kalinowski 1810 D I/B/1a WI; Feodor Kalinowski, Tadeus Kalinowski przeł. XVIII/XIX w. KWD 692 WI; Stanisław po Teodorze Kalinowski 1846 Br III/S/1 WI

Kamiński: Laboriosi Alberti Kamienski 1721 Bk I/B/2 WI; Pauli Kamienski 1732 Br I/B/2a PA; Adalberto Kamiński 1804 D I/B/1a SO; Hon: Adalberto Kamieński 1809 D I/B/1a WI; Jozef Kaminski przeł. XVIII/XIX w. KWD 692 WI; Marcin po Woyciechu Kamięski, Jan po Jozefie Kamienski, Jan po Tadeuszu Kamieski 1846 Br III/S/1 WI

Kamiński Czołzuk: Michaelis Kamienski dicti Czołzuk 1729 Br I/B/2a PA

Kamiński v Tomezuk: Jan po Wawrzyncu Kamienski v Tomczuk 1846 Br III/S/1 PA

Karolasik: Honestus Martinus Karolasik 1661 M 1708-1-153, k. 27 v.WI

Kisiel: Ba[z]ylii Kisiel $1733 \mathrm{Br}$ I/B/2a JA

Koczuk: Laboriosi Joannis Koczuk 1664 Br I/B/1 OT

Koniuch: LL. Michaelis Koniuch et Catharinae 1730 Br I/B/2a PA; Laboriosorum Simonis Koniuch 1742 Ł I/B/2 AB; Gregory et Sophiae Koniukow 17691742 Ł I/B/4 AB; Jacob Koniusch, Danilo Kozuch przeł. XVIII/XIX w. KWD 692 AB; Wawrin Koniuch przeł. XVIII/ XIX w. KWD 692 PU

Koniuszek: Petri Koniuszek 1723 Br I/M PU

Koniuszuk: Laboriosorum Michaelis Koniuszuk et Catharinae $1725 \mathrm{Br}$ I/B/2a PA

Koniuszyk: Piotr Koniuszyk y Anton 1692 KGB 52, k. 202 PU; Michaelis Koniusik et Catharinae $1733 \mathrm{Br} \mathrm{I} / \mathrm{B} / 2 \mathrm{a} \mathrm{PA}$

Korobus: Molitoris dicto Korobus 1650 M 1708-1-141, k. 306 WI

Korpaczyk: Honestus Wasil Korpaczyk filius olim Joannis 1665 M 1708-1-158, k. 256 v PA

Kosciuczyk: Honestus Venceslaus Kosciucyk 1663 M 1708-1-43, k. 273 WO

Kosczuk: Honestos Stanislaum Bartholomaeum Kosczuki 1599 MK143, k. 199 v.-200 WO

Kostenczuk: HH. Francisci et Anastasiae Kostenczukow 1780 Ł I/B/4 AB

Kowal: R. Krzysztof syn Grzegorza Kowala y benedykt Parobek tegoż 1692 KGB 52, k. 187 TO

Koziel/Kozioł: Iwan Koziet Mtynarz 1667 AR XXV 362a, k. 9 v. PU; Panasa Kozła żona syn y corka 1716 KGB 44, k. 378 v. PU; Mikolei Koziol, Roman Kozi, Kornilo Koziol przeł. XVIII/XIX w. KWD 692 PU

Kozluk: Panas Kozłuk z bratem 1692 KGB 52, k. 202 PU; Bartolomai et Franciscae Kozlukow 1769 D I/B/1WO; HH. Nicolai et Mariannae Kozlukow 1769 Ł I/B/4 AB

Kozlowicz: Honesti Joannis Kozłowicz 1667 M 1708-1-45, k. 155 v. PU

Kozłowski: Joannis Kozłowski et Justinae 1756 Bk I/B/4 ON; Honestum Bartholomai et Franciscae Kozłowski 1773 D I/B/1 WO; Karol Kozłowski Młynarz 1846 Br III/S/1 OT

Kożuch: Hon Christophori et Julianae Kozuchowie 1779 D I/B/1 ON 
Kraszewski/Kraszowski: Joannes Kraszewski 1727 Br I/B/2a PA; Honestorum Joannis Kraszowski $1728 \mathrm{Br} \mathrm{I} / \mathrm{B} / 2 \mathrm{a} \mathrm{PA}$

Krupka/Krupko: Sienko Krupko 1558 AVAK IV 27 KR; Sienko Krupka 1563 PKGE II 407 KR; Honestus Sienko Krupko 1573 M 1708-1-202, k. 424424 v. KR

Krupka Decewicz: olim honesti Sieńko Krupka Dzieczewicz 1600 M 1708-1-19, k. 117 v. KR

Kumat: Wawrzyniec Kumat 1661-1664 AR XXV 361 NE; Wawrzyniec Kumak 1667 AR XXV 362a, k. 4 NE

Kunicki: Honesto Paulo filio Onacko Kunicki 1693 M 1708-1-59, k. 154 PA; Basilii Kunicki et Mariannae 1708 Br I/B/2a NE; Kunnicki z żona 1716 KGB 44, k. 378 NE; Josephi Theclae Kunickich 1768 Bk I/B/5 NE; Petri Kunicki 1727 Bk I/B/3 SO; Piotr Kunicky, Mikolay Kuniki, Anton Kunicky przeł. XVIII/XIX w. KWD 692 NE ; Piotr po Macieiu Kunicki 1846 Br III/S/1 BU; Jan Kunicki Prawosławny 1846 Br III/S/1 AB; Antoni po [Mateuszu - wykreślone] Adamie Kunicki, Jan po Jozefie Kunicki 1846 Br III/S/1 NE

Kuśnierz: Kusnierz z Jarmak[...] 1681 M 1802-1-1, k. 189 v. JA

Kuźmiak: laboriosorum Jozephi Kuzmiak et Helenae 1733 Bk I/B/3 SO

Laszuk: Jaszko Laszuk przeł. XVIII/XIX w. KWD 692 AB

Latinik: Żocha Latynika synow [2] 1716 KGB 44, k. 379 WO; Andreae et Agnete Latinikow $1772 \mathrm{D} \mathrm{I} / \mathrm{B} / 1 \mathrm{WO}$

Leskowicz: Laboriosi Valentini Leskowicz 1709 Bk I/B/2 TO

Lewkowski: Laboriosorum Andreae Lewkowski et Marcellae 1763 Bk I/B/5 SO

Lewonik: Honestus Philip Lewonik Molendinator 1645 M 1708-1-137, k. 208 v. ŻE; Iwan Parfien Lewoniki 1667 AR XXV 362a, k. 5 ŻE

Litwin: HH Laurenty Litwin et Theodorae $1680 \mathrm{Br}$ I/B/1 JA; Maxim Litwin z żona 1716 KGB 44, k. 377 v. BU; laboriosi Maximi Litwin et Theodora 1717 Br I/B/2 BU

Lubiński: Laboriosi Jacobi Łubinski 1745 Bk I/B/3 SO

Lukiańczuk: Perti et Annae Lukianczukow 1776 D I/B/1 ON

Mackiel: Laboriosum Josephi Mackiel et Margarithae 1699 Br I/B/1 BU; Josephi Mackiel et Margeritae $1702 \mathrm{Br}$ I/B/1

Maksimik: Laboriosi Nicolai Maxsimik $1688 \mathrm{Br}$ I/B/1 WY

Malinowski: Lucae Malinowski 1722 Br I/M TO; Laboriosorum Adalberti Malinowski et Mariannae 1766 Bk I/B/5 SO; honesto Faustinus Malinowski 1799 D I/B/1a WO; Hon. Faustino Malinowski $1809 \mathrm{D} \mathrm{I} / \mathrm{B} / 1 \mathrm{a}$ WO

Maliński: Laboriosor Martini Malinski et Zofiae 1730 Bk I/B/3 WO

Malosicz: mlinarze Klimko Malosicz s siabrami swemi 1563 PKGE II 411 ŻE

Materski: Franciscae Materski 1756 Bk I/B/4 SO; Michal Materski przeł. XVIII/XIX w. KWD $692 \mathrm{SO}$

Matuch: Kazimir Matuch, Woytek Matuch, Franz Matuch przeł. XVIII/XIX w. KWD 692 PA

Marciniak: Gregorii Marciniak et Dorothae 1679 Bk I/B/1b SO

Marcinik: Laboriosi Gregorii Maczynik 1658 Br I/B/1 TO; Honestus Albertus Marcinik 1666 M 1708-1-158, k. 636 TO; R. Grzegorz Marciniak z żona 1692 KGB 52, k. 187 v. TO; Laborior. Pauli Marcinik et Ter[e]sae 1760 D I/B/1 WO

Marciniuk: HH. Joannis Margarithae Marcianiukow 1769 Ł I/B/4 AB 
Markowicz: Honestus Georgius Markowicz 1607 M 1708-1-98, k. 188 v. SO

Markowienie: Georgium, Stanislaum, Christopherum Markowienieta 1607 M 1708-1-98, k. $260 \mathrm{SO}$

Markowski: Catharinam olim Gregorij Markowski de Villa Burkaty 1725 Br I/M BU; Lab: Philippi Markowski et Annae $1726 \mathrm{Br}$ I/B/2a PA

Marmol: Iwan Marmot z żoną 1716 KGB 44, k. 379 WO

Matysiak: Honesto Josepho Matysiak 1800 D I/B/1a WI

Matysik: Woyciech Matysik 1661-1664 AR XXV 361 WI

Matysiuk/Matyszuk: Woytek Matysiuky siostra 1716 KGB 44, k. 378 v. WI; Joannes Josepho Matisiuk 1805 D I/B/1a WI Hon. Josepho Matyszuk 1810 D I/B/1a WI

Mazur: Augustyn y Marcin Mazurowie 1661-1664 AR XXV 361 SO

Mazurczyk: Honestus Simon Mazurcik 1648 M 1708-1-37, k. 382 SO

Meleczuk/Milejczuk: Laboriosi Basilii Mileyczuk et Hapa 1706 Bk I/B/2 WY, laboriosi Bazily Meleczuk et Apolloniae 1709 Bk I/B/2 WY

(Me)tropolit: Sigismundum Tropolitum 1638 MK183, k. 56 v.TO; R. Woyciech Metropolit z Anna corka, R. Michat Metropolit z żona 1692 KGB 52, k. 187 TO; Gregorii Tropolit $1723 \mathrm{Br}$ I/B/2a TO; laboriosi Christophori Tropolit et Christinae 1718 Br I/B/2 BU; laboriosi Christophori Tropolit et Cristinae $1723 \mathrm{Bk} \mathrm{I} / \mathrm{B} / 3 \mathrm{ON}$

Michalczuk: H Gregorii et Magdalenae Michalczukow 1764 D I/B/1 SO; Honesti Joanni et Apolonia Michalczuka 1764 D I/B/1 WI; H[ones]tor[um] Jacobi et Eleonorae Michalczukow $1779 \mathrm{D} / \mathrm{I} / \mathrm{B} / 1$ ŻE

Michel: Joannis Michel et Oximae $1647 \mathrm{Br}$ I/B/1 PA

Mielczuk: R. Bazili Mielczuk 1692 KGB 52, k. 188 WY

Mielech/Mieloch: Simonis Mieloch 1717 Br I/B/2a PA; Simonis Mielech 1721 Br I/B/2a PA

Mieleszak: Joannem filius Laurenty Mieleszak et Reginae $1696 \mathrm{Br}$ I/B/1 BU

Mieleszuk: Szymko Meleszuk z żoną 1716 KGB 44, k. 379 PA

Mikołajczuk: Mikołayczukow 2 y siostra 1716 KGB 44, k. 379 ŻE

Milej: Laboriosi Joannis Miley 1668 Br I/B/1 WY

Miloicz: Laboriosi Procopii Miloicz $1656 \mathrm{Br} \mathrm{I} / \mathrm{B} / 1 \mathrm{WY}$

Miskowicz: Jarosza Miskrowicz, s iego potuzniki 1563 PKGE II 409 NE

Mochnowicz: Basili Mochnouicz $1731 \mathrm{Br} \mathrm{I} / \mathrm{B} / 2 \mathrm{a}$ JA

Moczulik: Bartholomaei Moczulik $1706 \mathrm{Bk} \mathrm{I} / \mathrm{B} / 2 \mathrm{WY}$

Moczula: Bartosz Moczuła z żona 1716 KGB 44, k. 379 PA; Bartholomaei Moczula $1723 \mathrm{Br}$ I/M PA

Mojsa: Maxim Moysa z żona 1692 KGB 52, k. 199 ŻE

Momociuk: R. Grzegorz Momociuk z żona 1692 KGB 52, k. 187 v. BU; R. Krzysztof Momociuk z zona tamże Maciey Momociuk brat 1692 KGB 52, k. 187 v. BU Laboriosi Gregorii Momoczuk et Heduigis 1692 Br I/B/1 BU; ex Laborioso Mathiae Momociuk et Dorothea Debouska 1693 Br I/B/1 BU

Momot: HH Stanislai Momot et Zophiae 1679 Br I/B/1 BU; Honestoru[m] Alberti Momot 1734 $\mathrm{Br} \mathrm{I} / \mathrm{B} / 2 \mathrm{BU}$

Moskal: Gres Moskal Żona Stara 1692 KGB 52, k. 202 NE 
Mucha: Honestus Christophorus Mucha 1681 M 1708-1-176, k. 237 v. BU; Laboriosi Christoferi Mucha 1682 Br I/B/1 BU; Honestorum Christophor Mucha 1684 Br I/B/1 BU

Nestorowicz: Niesthorowiczy 1558 AVAK IV 27

Nielchowic: Honestus Stephan ol Sidor Nielchowic 1651 M 1708-1-141, k. 747

Nieroda: Jan po Mikołaiu Nieroda l. 411846 Br III/S/1 BU

(N)iwiński: Laboriosi Odochim Niwinski ex Prouincia Biała Rus 1676 Br I/B/1 BU; HH. Joachimi Iwinski 1679 Br I/B/1 BU; Laboriosi Otdachim Iwinski 1687 Br I/B/1 BU

Noroziuk: Stephani et Annae Noroziukow 1764 D/I/B/1 ŻE

Odachim: laboriosi Mathiae Odachim 1712 Br I/B/2 BU; Laboriosi Mathiae Dachim 1724 Br $\mathrm{I} / \mathrm{B} / 2 \mathrm{BU}$; olim Mathiae Odachim $1727 \mathrm{Br} \mathrm{I} / \mathrm{B} / 2 \mathrm{BU}$

Oldachimczuk/Ołdakimczuk: Laboriosoru Mathiae Adachimczuk 1714 Br I/B/2a WY

Olesiejczuk: Laboriosi Martini Olesieyczuk 1707 Br I/B/2 BU

Olędzki: Macey Olendski przeł. XVIII/XIX w. KWD 692 JA

Onacko: Honesto Simoni Onaczko Molendinatori 1676 M 1708-1-172, k. 13 ON; Laboriosi Nicolai Onacko et Christinae 1690 Br I/B/1 PA; Mikołay Onacko żona y Brat 1692 KGB 52, k. 199 PA

Onackowicz: Jan Onackowicz 1667 AR XXV 362a, k. 5 ON

Ondryk: Laboriosi Joannis Ondrik 1645 Br I/B/1 BU; Joannis Undryk 1653 Br I/B/1 BU; Laboriosi Joannis Ondryk 1659 Br I/B/1 BU Mathias Undrik 1692 Br I/B/1 BU

Osmolski: Prouidus Martinus filius memorati Andr[eae] Osmolski 1607 M 1708-1-98, k. 260 SO; Nli Gregorio ol Martini Osmolski de Solniki herdi 1685 M 1708-1-182, k. 245 v. SO; Petri et Eduigis Osmolskich 1763 D I/B/1 SO; Hone: Paulo Osmolski 1810 D I/B/1a SO; Nlis Alberti Osmolski et Christinae Kiersnowska 1660 Br I/B/1 BU; Nobilium Stanislai Osmolski et Annae Pietkiewiczowna $1701 \mathrm{Br}$ I/B/1 BU; Gnosi Dni Stanislai Osmolski et Gnosa Dnae Annae Piętkiewiczowa 1706 Br I/B/2 BU; Laboriosi Nicolai Osmolski 1706 Bk I/B/2 WI; Woyciech po Janie Osmolski, Pawet Osmolski Oyciec, Jakob po Piotrze Osmolski, Jan po Jakobie Osmolski $1846 \mathrm{Br}$ III/S/1 SO

Otap(a): Stephani Otap 1647 Br I/B/1; Honesti Laurentii Otap molendinatoris 1672 M 17081-49, k. 321 OT; Petri Otap et Catharinae 1710 Br I/B/2a OT; Maciey Otapa z żona, Jozef Otapa z żona y siostra, Piotr Otapa z żona 1716 KGB 44, k. 377 v. OT

Otapik: Christophori Otapik 1653 Br I/B/2a; Wawren Otapik 1681 M 1802-1-1, k. 189 v. OT; R. Maciey Otapik przy tym brat Jozef 1692 KGB 52, k. 188 OT

Otapiuk: Mathia Otapiuk et Anna Szcygielska 1692 Br I/B/1 OT; Petri Otapiuk 1725 Br I/B/2a OT

Owsiej: Pauli et Teressiae Ousiejow 1768 D I/B/1 WO; H Pauli et Teressiae Osiejow 1774 D I/B/1 WO; Pauli et Teressiae Ousiejow 1777 D I/B/1 WO; honesto Adalberti Owsiey 1803 $\mathrm{D} \mathrm{I} / \mathrm{B} / 1 \mathrm{a} \mathrm{WO}$

Owsiejuk: Adalberto Owsiejuk 1805 D I/B/1a WO; Woyc Owszejuk przeł. XVIII/XIX w. KWD $692 \mathrm{WO}$

Owsieniuk: honesto Adalberto Owsieniuk 1799 D I/B/1a WO

Pac: Honestus Joannes filius olim Pauli Pac 1651 M 1708-1-141, k. 491 v. PA

Paczewic(z): Honestum Leonardum Pacziewic 1599 MK143, k. 194 v. PA; Honestus Joannes filius olim Pauli Paczeuicz 1671 M 1708-1-168, k. 434 PA 
Pobrane z czasopisma Studia Bia?orutenistyczne http://bialorutenistyka.umcs.pl Data: 26/04/2023 13:05:36

Panas: Laborios Nicolai Panas 1766 Ł I/B/4 AB

Panasiuk: Martini Panasiuk 1760 Ł I/B/2 PU; Laboriosor Nikolai Panasiuk 1747 Ł I/B/2 AB; honestor Josephi Panasiuk 1771 Ł I/B/4 AB

Pawlak Stasiłko: Joannis Pawlak Stasilko $1700 \mathrm{Br}$ I/B/1 PA

Pawluczuk: Basilio Pawluczuk Christophori filio 1810 D I/B/1a WO

Pawluk: Roman Pawluk s curko 1692 KGB 52, k. 202 PU

Pawłowicz Semenik: Honestis Hyacynthy Pawlowicz Semenik 1681 M 1708-1-176, k. 503 PA

Petroszuk: Joziuk Petroszuk przeł. XVIII/XIX w. KWD 692 PA

Pieczeński: Laboriosi Alberti Pięczenski1682 Br I/B/1 JA

Pieczewicz: Iwan Pieczewicz 1558 AVAK IV 27

Pikula: Laboriosor Constant[...] Pikuła 1752 Ł I/B/2 PU

Piotraszko: Mikołaia Piotraszka 1692 KGB 52, k. 188 WY; lab Nicolao Pietraszko 1699 Br $\mathrm{I} / \mathrm{B} / 1 \mathrm{WY}$

Piotrowski: Franciszek po Jozefie Piotrowski 1846 Br III/S/1 PA

Pluszcz: Eliae Pluszcz $1704 \mathrm{Br} \mathrm{I} / \mathrm{B} / 2 \mathrm{a}$ OT

Pokinbaba: Bartholomei Pokinbaba $1654 \mathrm{Br}$ I/B/1 WY

Poletylo: Alberto Poletiło $1689 \mathrm{Br} \mathrm{I} / \mathrm{B} / 1 \mathrm{JA}$

Pop: Chotian Pop 1599 MK143, k. 189 v. JA

Przystupa: Honestum Andream Przistupa 1599 MK143, k. 195 BU

Puchacz: Puhacz 1558 AVAK IV 27 PU; mlinarz Wasko Pachacz 1563 PKGE II 408 PU; Utciwy Wasko Puhac Mtynarz 1662 M 1708-1-42, k, 321 v. PU; Wasko Puhacz 1667 AR XXV 362a, k. 5 PU; Laboriosi Maximi Puhacz et Mariannae 1714 Br I/B/2a PA

Puchaczowic Chylewic: Honesto Iwan Radywon Puhaczowic Chylewic 1663 M 1708-1-43, k. 455 v. JA

Puchaczyk: Laboriosus Andreas Puhaczyk 1618 M 1708-1-31, k. 635 PU; Honestus Lucas Radywon Puchaczyk 1690 M 1708-1-57, k. 313 JA; Panas Puchaczyk zona 1692 KGB 52, k. 202 PU

Puchalski: Albertus Bartholomaeus filii ol Felicis Puchalski Molitor 1639 M 1708-1-130, k. 8 v. WO; Pauli Puchalski et Mariannae 1705 Bk I/B/2 WO; Catharinam olim Thomae Puchalski de Villa Woytkowicze 1725 Br I/M WO; Stephani et Annae Puchalskich 1772 D/I/B/1 ŻE; Htor Jacobi et Antoninae Puchalskich 1777 D I/B/1 WO; Franciszek po Franciszku Puchalski $1846 \mathrm{Br}$ III/S/1 PA

Puscik/Puszczyk: Laboriosi Gregorii Pusczyk 1645 Br I/B/1 PA; Honesti Gregorius et Andreas filii Honesti Gregorii Puscik 1661 M 1708-1-153, k. 5 v.- 6 PA

Pusczyc: Honestus Gregorius Puscyc 1645 M 1708-1-137, k. 321 v. PA

Radionik: Onisko Radionik Brat y Siostra 1692 KGB 52, k. 198 v. JA

Radywonczuk: Iwan Nadywonczuk z żona 1716 KGB 44, k. 379 PA, Iwan Radywonczuk z żona Brat y dziewka iego $1716 \mathrm{KGB} 44, \mathrm{k} .378 \mathrm{JA}$

Radywonik: Honesto Stephano Radywonik 1690 M 1708-1-57, k. 99 v. JA

Radziwon: Joannis Radziwon $1813 \mathrm{Br}$ I/D/1 JA

Reczka: Sidor Reczka 1558 AVAK IV 27

Rehorczuk: Ant Reborczuk przeł. XVIII/XIX w. KWD 692 AB; Jan Rehorczuk przeł. XVIII/ XIX w. KWD 692 PA 
Rogucki: Francisci et Ludovicae Roguckich 1780 D I/B/1 WI; Mikołay po Mikołaiu Rogucki $1846 \mathrm{Br} \mathrm{III} / \mathrm{S} / 1 \mathrm{BU}$

Rojewicz: Jermak Roiewicz 1563 PKGE II 408 JA

Rokita: laboriosorum Gregorii Rokita $1714 \mathrm{Br} \mathrm{I} / \mathrm{B} / 2 \mathrm{a} \mathrm{WY}$

Romanczuk: Philippi Romanczuk et Annae 1710 Br I/B/2a PA; Christophori Romańczuk et Mariannae 1725 Br I/B/2a PA; Laborios Nicolai Romanczuk 1744 Ł I/B/2 AB

Romanowicz: mlinarz Pacz Romanowicz 1563 PKGE II 409 PA

Romanowski: Petri Romanowski $1702 \mathrm{Br}$ I/B/2 BU

Rutkowski: Michal Rutkowski przeł. XVIII/XIX w. KWD 692 BU

Ryszkowski: Hon: Laboriosi Simonis Riskowski 1703 Bk I/B/2 TO ; Adami et Evae Ryczkowski 1777 D I/B/1 TO; Joanni Ryszkowski 1809 D I/B/1a TO; Jędrzey Ryszkowski, Jan Ryszkowski przeł. XVIII/XIX w. KWD 692 TO; Antoni po Janie Ryszkowski, Jozef po Janie Ryszkowski, Franciszek po Janie Ryszkowski, Jozef po Andrzeiu Ryszkowski $1846 \mathrm{Br}$ $\mathrm{III} / \mathrm{S} / 1 \mathrm{TO}$

Sawicki: Joan[n] is Sawicki 1727 Bk I/B/3 NE; Laboriosorum Lucae Sawicki et Annae 1759 Bk I/B/4 ON; Hon: Petro Sawicki 1809 D I/B/1a SO; Piotr Sawitzki przeł. XVIII/XIX w. KWD 692 SO; Wawrzyniec po Piotrze Sawicki, Pawet Sawicki Brat 1846 Br III/S/1 SO

Sawka: Famator Lucae et Annae Sawkow 1764 Bk I/B/5 ON; Lucae Annae Sawkow 1767 Bk I/B/5 ON; Stephani et Zofiae Sawkow 1777 D I/B/1 SO

Sawko: Szymon Sawko $1846 \mathrm{Br}$ III/S/1 AB

Semeniuk: Stefan Semenik, Fedor Semenik z żona 1692 KGB 52, k. 199 PA; Kazimierz Semeniuk 1716 KGB 44, k. 378 v. ON

Serwinowic: Lukasz z Stepanem Sewinowic 1661-1664 AR XXV 361 NE

Sidorczuk: Jakob po Stefanie Sidorczuk $1846 \mathrm{Br}$ III/S/1 PA

Siedlecki: mlinarz Sczesni Siedlieczki 1563 PKGE II 410 WO; Honesto Maximo Siedlecki de Zegunie molendinatori 1684 M 1708-1-53, k. 29 v. ŻE; Laboriosi Michaelis Siedlecki 1720 Bk I/B/2 WI; Laboriosi Andreae Siedlecki 1724 Bk I/B/3 TO; Adae Siedlecki et Petrunellae 1730 Bk I/B/3 SO; Martini Siedlecki et Margarethae 1793 Bk I/B/5 WO; Honesto Martino Siedlecki 1798 D/I/B/1a ŻE

Sieklucki: R. Jan Sieklucki z żona, R. Szczepan Sieklucki z żona 1692 KGB 52, k. 187 WO; Siekluckiego syn 1716 KGB 44, k. 379 WO; Fa: Michaelis Sieklucki 1790 Bk I/B/5 SO; Jan po Stanisławie Sieklucki, Jozef po Stanisławie Sieklucki, Grzegorz Sieklucki Prawosławny $1846 \mathrm{Br} \mathrm{III/S} / 1 \mathrm{SO}$

Sielicki: Laboriosor Antonii Casimirik? Sielicki 1717 Bk I/B/2 ON

Siemieniuk: Laboriosi Laurentii Siemieniuk et Ahapiae 1703 Bk I/B/2 ON; Basiliy Siemieniuk et Annae $1707 \mathrm{Br} \mathrm{I} / \mathrm{B} / 2 \mathrm{a} \mathrm{PA}$

Sierko: Honestus Stephanus Sierko 1678 M 1708-1-174, k. 135 NE

Skłodzik: R. Walenty Skłodzik komornik P. Arwatowicza także y Regina dziwka 1692 KGB 52, k. 188 WY

Skotnicki: Jozef Skotnicki z żona 1716 KGB 44, k. 379 PA; Laboriosi Josephi Skotnicki 1723 $\mathrm{Br} \mathrm{I} / \mathrm{B} / 2 \mathrm{a} \mathrm{PA}$

Sokołowski: Laboriosorum Adalberti Sokołowski et Mariannae 1761 Bk I/B/4 ON; Alberti et Mariannae Sokołowskich 1763 Bk I/B/5 SO 
Solniczyk: Laboriosus Stanislaus Solhnczik 1601 M 1708-1-91, k. 361 SO

Solnik: mlinarze Woithek, Pawel s braczia Solniki 1563 PKGE II 411 SO; Honestus Georgius filius olim Marci Solnik 1599 M 1708-1-18, k. 193 v. SO; Laboriosus Albertus Solnik 1645 M 1708-1-137, k. 234 SO; Laboriosorum Gregorii Solnik et Dorotheae 1692 Bk I/B/1b SO

Stachnik: Laboriosi Leonardi Stachnik $1673 \mathrm{Br}$ I/B/1 WY

Stasileńki: Honesti Wawryn Stasilenki 1669 Br I/B/1 ME

Stasilczuk: Joannis Stasilczuk et Cristini 1709 Br I/B/2a PA; Laboriosi Laurenty Stasilczuk $1701 \mathrm{Br} \mathrm{I} / \mathrm{B} / 1 \mathrm{BU}$; Bartholomei Stasilczuk $1712 \mathrm{Br} \mathrm{I} / \mathrm{B} / 2 \mathrm{a} \mathrm{WY}$

Stasilczuk Dumak: Laboriosus Paulus Stasitczuk Dumak 1698 Br I/B/1 BU

Stasilczyk: Honesto Wawryn Stasilczyk 1666 M 1708-1-158, k. 637 v. ME; Laboriosi Laurentu[m] Stasilcik $1675 \mathrm{Br} \mathrm{I/B/1} \mathrm{ME}$

Stasilczyk Wysocki: Francisco Stasilczik Wysocki 1681 M 1708-1-176, k. 503 WY

Stasiłko: Laboriosi Laurentii Sztasitko 1661 Br I/B/1 ME; Wawrzyniec Stasiełko 1667 AR XXV 362a, k. 4 ME; Laboriosi Laurentii Stasitko 1671 Br I/B/1 ME; Laboriosi Simonis Stasitko 1663 Br I/B/1 WY; R. Franciszek Stasiłko z Bratem Bartłomieiem 1692 KGB 52, k. 188 WY; u Fronca Stasiłka corka 1716 KGB 44, k. 377 v. WY; Gres Stasiłko Żano 1692 KGB 52, k. 202 NE; Laboriosi Simonis Stasitko 1674 Br I/B/1 BU; Laboriosi Simonis Stasytko 1678 Br I/B/1 BU; R. Wawrzyniec Stasitko Młodzian 1692 KGB 52, k. 187 v. BU; Bartos Stasiłko z zona y parobkiem 1716 KGB 44, k. 377 v. BU; laboriosi Bartholomei Stasiłko 1720 Br I/B/2 BU; Laboriosorum Martini Stasitko 1730 Br I/B/2a WY; Pawet Stasitko 1692 KGB 52, k. 199 PA; Hon: Simonis Stasitko 1729 Br I/B/2a PA

Stasiuk: Szymko Stasiuk z żona 1716 KGB 44, k. 379 SO; Laboriosi Simonis Stasiuk et Annae $1721 \mathrm{Bk} \mathrm{I} / \mathrm{B} / 2 \mathrm{SO}$

Surojeskowicz: Mlinarze Jurek Sacz, Simek Smoieskowicz s potuszniki 1563 PKGE II 409 WY

Szadkowski: Andrzey po Mikołaiu Szadkowski 1846 Br III/S/1 PU

Szancuk: Laboriosus Joannes Szancuk 1655 M 1708-1-39, k. 231 SO

Szczepanik: Floryan Sczepanik z uczestnikami 1667 AR XXV 362a, k. 5 SO; olim Honesti Jacobi Sczepanik 1664 M 1708-1-156, k. 448 WO

Szczepaniuk: Honestus Florianus Sczepaniuk 1645 M 1708-1-137, k. 49 SO; Honestus Jacobus Sczepaniuk 1662 M 1708-1-153, k. 360 WO

Szczerbakow: Michat Szczerbakow [dopisek- wybyt], syn Konstantyn [dopisek - prawostawny], Żona prawostawna $1846 \mathrm{Br}$ III/S/1 MA

Szczęsny: Woyciech Szczęsny 1661-1664 AR XXV 361 OT

Szczęśniuk: Famati Alberti Szczesniuk et Marinam Kadtubowska 1667 Br I/B/1 OT

Szepietowski: Laboriosorum Simonis Szepietowski et Mariannae 1760 Bk I/B/4 SO

Szlachatczyk/ Szlachecczyk: Mateusz Stachatcyk 1661-1664 AR XXV 361 PA; Honesti Mathaei Slacheccyk 1668 M 1708-1-161, k. 420 v. PA

Szlachetka: Matheusz Szlachetka z uczestnikami 1667 AR XXV 362a, k. 4 PA

Szpaczuk: Filium Casimiri et Julianae Szpacukow 1772 D I/B/1 ON

Szpak: Lab Casimiri et Juliannae Szpakow 1775 D I/B/1 ON; honesto Casimiro Szpak 1799 D I/B/1a ON; Michal Spak, Casimir Spak przeł. XVIII/XIX w. KWD 692 ON

Szpakowski: Laboriosorum Joannis Szpakowski et et Justinae 1759 Bk I/B/4 ON; Fa[ma] tor Cazimieri Szpakowski et Julianae 1781 Bk I/B/5 ON; Hon. Francisco Szpakoski 1808 
D I/B/1a ON; Hon. Christophoro Szpakowski 1810 D I/B/1a TO; Maciey po Kazimierzu Szpakowski, Jozef Szpakowski $1846 \mathrm{Br}$ III/S/1 ON

S(z)urma: U Surmy Parob y dziewka 1716 KGB 44, k. 377 v. BU; Laboriosus Christophorus Surma 1707 Br I/B/2 BU; Laboriosorum Thomae Surmacz et Agathae 1724 Br I/B/2 BU; Laborios Thomae Szurma et Agnetis 1727 Br I/B/2 BU; Jan Surma przeł. XVIII/XIX w. KWD 692 BU; Marcin po Janie Szurma 1846 Br III/S/1 BU

Szymczuk: Thomae et Marcellae Szymczukow 1780 D I/B/1 SO; Honesto Paulo Szymczuk 1809 D I/B/1a SO; Tomek Szimczuk, Jędrzey Szimczuk, Jacob Syminczyms przeł. XVIII/ XIX w. KWD 692 SO

Szymczuk Osmolski: Stanisław po Andrzeiu Szymczuk Osmolski 1846 Br III/S/1 SO

Śliwiński: Stephani et Mariannae Sliwinskich 1765 D I/B/1 WI

Śliwowski: Mathias Sliwowski $1705 \mathrm{Br} \mathrm{I} / \mathrm{B} / 2 \mathrm{a} \mathrm{JA}$

Ślusarczuk: Andreae Slusarczuk $1725 \mathrm{Br} \mathrm{I} / \mathrm{B} / 2 \mathrm{a}$ WY

Ślusarczyk: Andreae Slusarczyk 1706 Br I/B/2a WY; Andreae Slusarczyk 1710 Br I/B/2 BU

Śpieszyński: Józew Spieszynsky s pasierzbica 1692 KGB 52, k. 202 PU; Honesto Josepho Spiszynski 1683 M 1708-1-52, k. 206 PU

Święty: Woytek Swiety z zona 1716 KGB 44, k. 377 v. BU; laboriosi Swięty et Heduigis 1713 $\mathrm{Br} \mathrm{I} / \mathrm{B} / 2 \mathrm{BU}$

Tarasiuk: Honestum Kopryan filium Honesti Trasiuk Mollitorem 1672 M 1708-1-49, k. 309 v. PU

Tołwiński: Stefan Tolwinski Prawosławny 1846 Br III/S/1 PU

Tomczuk: Danilo Tomczuk przeł. XVIII/XIX w. KWD 692 PA; Anton po Daniele Tomczuk, Kazimierz po Janie Tomczuk 1846 Br III/S/1 PA

Tonaczkowienie: HH. Gregory Tonaczkowienie et Marinae Jucianka 1680 Br I/B/1 WY

Torula/Turula: Stanislaus Ioannes Sigismundus Torule 1599 MK143, k. 197 TO; Thomae Turula $1654 \mathrm{Br} \mathrm{I} / \mathrm{B} / 1 \mathrm{TO}$

Trelczuk: R. Symon Trelczuk z żona 1692 KGB 52, k. 187 SO

Tropoliciuk: laboriosum Christophorum Tropolicuk 1717 Br I/M TO

Trzpetunik: Szymon Trzpetunik z żona 1692 KGB 52, k. 187 v. TO

Tur: R. Sebastyan Tur z żona U Tegoz Maryanna Komornica 1692 KGB 52, k. 187 WO; Jędrzey Tur 1716 KGB 44, k. 377 v. WY; Htr Adami et Annae Turow 1777 D I/B/1 WO; honesto Christophoro Tur 1803 D I/B/1a WO; Raphael Tur, Christoph Tur przeł. XVIII/XIX w. KWD 692 WO; Stanisław po Krysztofie Tur, Jan po Krysztofie Tur, Jozef po Andrzeiu Zoch $1846 \mathrm{Br}$ III/S/1 WO

Turulowic: mlinarze Matis, Pawel, Piotr Turulionic 1563 PKGE II 410 TO

Tur(z)yk: Honesto Alberto ol Joannis Turzyk 1663 M 1708-1-43, k. 371 v.WO; honesto Michaeli filio Alberti Turryk 1688 M 1708-1-188, k.199 WO

Tuszewicki: Honestus Comath Thuszewiczki Molitor 1581 M 1708-1-205, k. 314 v; Wasko Tuszewicki zona y siostra 1692 KGB 52, k. 199 ON; Laboriosi Lucae Tuszewicki 1719 Bk I/B/2 ON; Famatorum Bartholomaei Tuszewicki et Marcellae 1757 Bk I/B/4 ON; Petri et Mariannae Tusiewickich 1769 D I/B/1 ON; Stephano Jusowicki 1808 D I/B/1a ON, Stefan Suszewicky, Jan Suszewicky przeł. XVIII/XIX w. KWD 692 ON; Wawrzynie[c] po Ludwi- 
ku Tuszewicki, Wawrzyniec Tuszewicki Prawosławny, Antoni po Stefanie Tuszewicki 1846

Br III/S/1 ON; Józef po Jakobie Tuszewicki Syn, Franciszek po Kazimierzu Tuszewicki $1846 \mathrm{Br} \mathrm{III} / \mathrm{S} / 1 \mathrm{PA}$

Tuszewicki Onacko: Honestum Danielem filium Joannis Onaczko Tusiewicki 1685 M 1708-1182, k. 525 v. ON

Tuszewicki Onackowicz: slachetny Jan Tuszeuicki Onaczkowicz 1666 M 1708-1-158, k. 448

ON; Honestum Joannem Tuszewicki Onackowicz 1678 M 1708-1-174, k. 390 ON

Tuszewicz: Famator Joannis Tuszeuicz et Annae 1785 Bk I/B/5; ON; Fa: Petri Tuszeuicz et Annae $1788 \mathrm{Bk} \mathrm{I/B} / 5 \mathrm{ON}$

Tymosiuk Czolzyk: Honesto Matochfaey Tymosuk Czolzyk 1668 M 1708-1-161, k. 420 v.PA

Tysowicz: Nauch Tyssowicz 1558 AVAK IV 27

Ustianik: Zachariam Vstianik 1599 MK143, k. 189 v. JA; Honestus Zacharias Ustianik 1601 M 1708-1-91, k. 36 v. JA

Walkołoch Żoch: Walkołoch Zoch z żona y brat 1716 KGB 44, k. 379 WO

Waloch: Iwan Walioch 1558 AVAK IV 28

Wasilczyk: Honesto Radiuon Wasilczyk 1662 M 1708-1-153, k. 346 PU

Wasiuczyk Puchaczyk: Radiwon Waszuczyk Puchalczyk 1667 M 1708-1-45, k. 405 v. JA

Wasiukowicz: Hawryło Wasiukowicz Młynarz, Kupryan Wasiukowicz Młynarz 1667 AR XXV 362a, k. 9 v. PU

Wawryn: olim Laurentij Wawryn $1725 \mathrm{Br} \mathrm{I} / \mathrm{M} \mathrm{BU}$

Wawryniuk: LL Joannes Wawryniuk et Zofiae $1731 \mathrm{Br} \mathrm{I/B} / 2 \mathrm{BU}$

Wawr(z)eniuk: Honestorum Josephi Waureniuk $1731 \mathrm{Br}$ I/B/2 BU; Anton Wawrzeniuk przeł. XVIII/XIX w. KWD 692 PA

Wietocha: Jakobi et Mariannae Uietochow 1768 D I/B/1 WO

Wietoszka/Wietuszka: ol Honesti Jacobi Wetoska 1663 M 1708-1-43, k. 371 v. WO; R. Jakub Wietuszka z żona 1692 KGB 52, k. 187 WO; Labor: Lucae Bietoszka et Sophiae $1727 \mathrm{Br}$ I/B/2 WO; Laboriosor Jacobi Wietosska et Mariannae 1761 D I/B/1 WO; Ho: Andreae et Catharinae Witouskie 1779 D I/B/1 WO ; Honestor Andreae et Catharinae Wetozków 1782 D I/B/1 WO; honesto Andreae Wetoszka 1802 D I/B/1a WO; Andreae Wetoska 1808 D I/B/1a WO; Jędrzey Woytaski, Faustin Wietoski przeł. XVIII w./ XIX w. KWD 692 WO; Franciszek po Tadeuszu Wietoszka l. 441846 Br III/S/1 WO

Wilczewski: Laboriosi Michaelis Wilczewski $1685 \mathrm{Br} \mathrm{I} / \mathrm{B} / 1 \mathrm{WY}$

Wilginia: Laboriosus Petrus Wilki[...]c 1608 M 1708-1-98, k. 542 WI; R. Matheusz Wilginia z żona, Kaspar Wilginia z żona 1692 KGB 52, k. 187 v. WI; Laboriosoru Jacobi Wilginia $1733 \mathrm{Br} \mathrm{I} / \mathrm{B} / 1 \mathrm{WI}$

Wilginia Matysiuk: $R$. Woyciech Wilginia Matysiuk z żona, przytym brat Jan Wilginuk 1692 KGB 52, k. 187 v. WI

Wilkin: mlinarz Siman Wilkin 1563 PKGE II 410 WI

Wilkinik: Matys y Grzegorz Wilkinikowie z uczestnikami 1667 AR XXV 362a, k. 5 WI

Wilkinowicz: Szymon Wilkimowicz 1558 AVAK IV 28 WI

Wiśniewski: Stanistaw po Ignacym Wisniewski 1846 Br III/S/1 BU

Wojtkowski: Antoni Woytkowski Folusznik 1846 Br III/S/1 OT 
Worobiuk: Fedor Worobiuk z bratem Semene[m] 1692 KGB 52, k. 202 PU

Woronka: Stanislai Woronka $1660 \mathrm{Br} \mathrm{I} / \mathrm{B} / 1 \mathrm{ME}$

Wronowski: Laboriosus Jacobus filius Janes Wronowski 1655 M 1708-1-39, k. 231 SO

Wróbel: laboriosorum Sidor Wrobel 1731 Ł I/B/2 AB; Honestor Theodori Wrobel 1786 Ł I/B/4 AB; Jan Wrobel przeł. XVIII/XIX w. KWD 692 AB; Jędrzey Wrobel, Wrobel Kazimir, Antony Wrobel przeł. XVIII/XIX w. KWD 692 PA, Michat po Andrzeiu Wrobel, Woyciech po Kazimierzu Wrobel 1846 Br III/S/1 PA

Wróblewski: Anastazia Coniux Sidori Wroblewski 1758 Ł I/B/2 AB

Wysocki: Joannes Wysocki 1689 Br I/B/1 WY, Laboriosoru[m] Martini Francu[k] Wysocki 1752 Bk I/B/4 WY; Adae et Rosaliae Wysockih 1769 D I/B/1WO

Zachar: Honesti Mathiae Zachar 1674 Br I/B/1 JA

Zacharczuk: Maciey Zacharczuk 1667 AR XXV 362a, k. 5 JA; Jasko Zacharcuk 1681 M $1802-$ 1-1, k. 189 JA; Woyciech Zacharcuk 1681 M 1802-1-1, k. 189 v. JA; Honestus Procopius olim Honesti Matthiae Zacharczuk 1690 M 1708-1-57, k. 263 v.JA; Laboriosi Alberti Zacharczuk 1693 Br I/B/1 JA; R. Woyciech Zacharczuk z żona 1692 KGB 52, k. 185 JA

Zacharczyk: Maciey Zacharczyk 1661-1664 AR XXV 361 JA

Zacharowicz: Honestus Mathias Zacharouicz Molendinator 1663 M 1708-1-41, k. 349 v. JA

Zajkoic: Honesti Lucae Zaykoic 1675 Br I/B/1 OT

Zalewski: Jan Zalewski przeł. XVIII/XIX w. KWD 692 PA; Karol po Janie Zalewski 1846 Br III/S/1 PA

Zaliwski: Jan Zaliski 1716 KGB 44, k. 379 PA; LL Alberti Zaliuski et Annae 1730 Br I/B/2a PA

Zieleniewski: Jakub Zieleniewski 1716 KGB 44, k. 379 SO; Pauli Zieleniewski 1732 Bk I/B/3 SO; F Stephani Zielenieski 1794 Ł I/B/5 SO; Hon: Gregorii Zieleniewski Stephani filii 1810 D I/B/1a SO; Honestorum Josephi et Evae Zielenieuskich 1767 D I/B/1WO; Michal Zewierski, Stefan Zelenowski przeł. XVIII/XIX w. KWD 692 SO; Wawrzyniec po Walendym Zieleniewski, Jan po Stefanie Zieleniewski, Grzegorz po Stefanie Zieleniewski [umart] $1846 \mathrm{Br} \mathrm{III} / \mathrm{S} / 1 \mathrm{SO}$

Zielenkowski: Adami Zielienkowski $1745 \mathrm{Bk} \mathrm{I} / \mathrm{B} / 3 \mathrm{SO}$

Zygmonciuk: R. Szymon Zygmonciuk Młodzian y Krzysztof brat przy nim 1692 KGB 52, k. 187 TO Żegun: Mikołay Żegun z żona 1692 KGB 52, k. 199 ŻE

Żegunia: mlinarze Jewlasz Zegunia, Iwan 1563 PKGE II 410 ON; Ivan Zegunya 1562 M 17081-4, k. 114 ŻE; mlinarz Iwan Zegwina 1563 PKGE II 407; Iwan Żegunia 1661-1664 AR XXV 361 ŻE; Antoni Zegunia z żona, Iwan Zegunia z żona 1716 KGB 44, k. 379 ŻE; Laboriosi Antonii Żegunia 1720 D Bk/I/B/2 ŻE; Pawel Żegunia, Jan Żegunia, Martin Żegunia, Jozef Żegunia przeł. XVIII/XIX w. KWD 692 ŻE; Adalbertus Martino Zegunia 1805 D/I/B/1a ŻE; Jan Żegunia Prawosławny, Jozef Żegunia Prawosławny, Piotr Żegunia Prawosławny, Wawrzyniec Żegunia Prawosławny, Jan Żegunia Prawosławny, Grzegorz Żegunia Prawostawny 1846 Br III/S/1 ŻE

Żegunicz: Żeguniczy 1558 AVAK IV 28 ŻE

Żoch: R. Pawet Żoch z żona, R. Bartosza Żocha 1692 KGB 52, k. 187 WO; Krys Zoch z żona, Macko Zoch 1716 KGB 44, k. 379 WO; R. Grzegorz Żoch z żona 1692 KGB 52, k. 187 ON; Gres Zoch z żona 1692 KGB 52, k. 199 ON; Famator Andreae Zoch et Agnes 1775 
Bk I/B/5 ON; Laboriosi Christophori Zoch et Maryannae $1720 \mathrm{Br}$ I/B/2 WO; honesto Martino Zoch 1799 D I/B/1a SO; Honesto Joanni Zoch Adami filio 1810 D I/B/1a WO; Jan Żak 1.lo., Jan Żak 2.lo., Jedrzey Zach przeł. XVIII/XIX w. KWD 692 WO; Antoni po Andrzeiu Zoch, Jan po Barttomieiu Zoch, Jakub po Janie Zoch, Jozef po Adamie Zoch, Jan po Adamie Zoch, Woyciech po Andrzeiu Zoch 1846 Br III/S/1 WO

Żoch Bartoszyk: Woyciech y Bartosz Zochowie Bartoszykowie 1667 AR XXV 362a, k. 5 WO

Żochowski: Famator Thomae Zochoski et Ludovicae 1777 Bk I/B/5 WO; Josephi et Barmarae Zochowskie 1767 D I/B/1 WO; Adami et Mariannae Żochouskie 1783 D I/B/1 WO

Żosiuk/ Żoszuk: Laboriosu Gregoriu Żosiuk 1655 M 1708-1-39, k. 231 WO; Honesto Alberto Żoszuk 1663 M 1708-1-43, k. 273 WO; R. Thomasz Zoszuk z żona, R. Woyciech y Marek Zoszuki Młodziani y Agniszka siostra Ich 1692 KGB 52, k. 187 WO; Jacubi et Cristinae Zosiukow 1765 D I/B/1 WO

Żuk: Franz Żuk przeł. XVIII/XIX w. KWD 692 WI

Żukowski: Żukowski: Hon. Francisco Zukowski 1808 D I/B/1a WI; Antoni po Franciszku Zukowski 1846 Br III/S/1 WI

\section{Źródła drukowane}

AVAK XIV Inventarz y lidzba skarbowa starostw Branskiego y Saraskiego 1558 [w:] Akty izdawajemyje Wilenskoju Archieołogiczeskoju Komissieju, Wilna 1888, s. 24-45.

PKGE II Uwołocznoje izmierienije gorodow Brianska i Saraża s prinadleżaszczimi k nim wołostiami, sostawlennoje Diewiałtowskim-Skoczkom w 1560-1563-m g. [w:] Piscowaja kniga Grodnienskoj ekonomii s pribawlenijami, II, Wilna 1882.

\section{Źródła rękopiśmienne}

AGAD Warszawa

AR XXV 361 Lustracja starostwa brańskiego z 1. 1661-1664, Dz. XXV nr 361

AR XXV 362a Inwentarz włości starostwa brańskiego z 1667 r. Dz XXV nr 362a

KGB 44 Księga grodzka brańska z 1. 1670-1726

KGB 52 Księga grodzka brańska z r. 1692, 1712

Ks. Ref. 58 Księga Sądu Referendarskiego z 1. 1780-1783

MK 143 Księga wpisów Metryki Koronnej z r. 1599

MK 183 Księga wpisów Metryki Koronnej z r. 1638

\section{AP Bialystok}

KWD 692 Kamera Wojenna i Domen, sygn. 692

\section{AD Drohiczyn}

Bk I/B/1b Księga chrztów par. Boćki z 1. 1677-1696 
Bk I/B/2 Księga chrztów par. Boćki z 1. 1698-1723

Bk I/B/3 Księga chrztów par. Boćki z 1. 1723-1748

Bk I/B/4 Księga chrztów par. Boćki z 1. 1748-1762

Bk I/B/5 Księga chrztów par. Boćki z 1. 1763-1803

Br I/B/1 Księga chrztów par. Brańsk z 1. 1644-1701

Br I/B/2a Księga chrztów par. Brańsk z 1. 1702-1734

Br I/M Księga małżeństw par. Brańsk z 1. 1709-1725

Br I/D/1 Księga zgonów par. Brańsk z 1. 1797-1816

Br III/S/1 Księga spisu parafialnego par. Brańsk z 1846 r.

D I/B/1 Księga chrztów par. Dołubowo z $1.1760-1783$

D I/B/1a Księga chrztów par. Dołubowo z 1. 1798-1816

Ł I/B/2 Księga chrztów par. Łubin z 1. 1725-1766

Ł I/B/4 Księga chrztów par. Łubin z 1. 1766-1790

Ł I/B/5 Księga chrztów par. Łubin z 1. 1791-1826

\section{НГАБ Мінск}

Księgi grodzkie brańskie: M 1708-1-4 z 1. 1562-1563; M 1708-1-18 z r. 1599; M 1708-1-19 z 1. 1600-1601; M 1708-1-31 z 1. 1617-1618; M 1708-1-37 z 1. 1648-1649; M 1708-139 z 1655 r.; M-1708-1-41 z 1. 1661-1663; M 1708-1-42 z 1. 1661-1662; M 1708-1-43 z 1663 r.; M 1708-1-45 z 1667 r.; M 1708-1-49 z 1. 1672-1673; M 1708-1-52 z 1683 r.; M 1708-1-53 z 1684 r.; M 1708-1-57 z 1690 r.; M 1708-1-59 z 1693 r.; M 1708-1-91 z 1601 r.; M 1708-1-98 z 1. 1607-1608; M-1708-1-130 z r. 1639; M 1708-1-137 z 1645 r.; M 1708-1141 z 1. 1650-1651; M 1708-1-153 z 1. 1661-1662; M 1708-1-156 z 1664 r.; M 1708-1-158 z 1. 1665-1666; M 1708-1-161 z 1. 1667-1668; M 1708-1-168 z 1. 1670-1671; M 1708-1171 z 1675 r.; M 1708-1-172 z 1676 r.; M-1708-1-174 z 1. 1678-1679; M-1708-1-176 z r. 1681; M 1708-1-182 z 1685 r.; M 1708-1-188 z 1688 r.; M 1708-1-192 z 1691 r.; M-17081-202 z 1. 1573-1574; M-1708-1-205 z r. 1581

M 1802-1-1 Księga miejska brańska z 1. 1676-1681

RA Enskilda 8636, Repozytorium Cyfrowe Poloników, [dostęp 8.07.2015] http://www. repcyfr.pl/dlibra/docmetadata?id=2561\&from=\&dirids $=1 \&$ ver_id $=2586 \& 1$ p $=11 \&$ QI$=$ !6CEF3C76C637897C3974EB25D255D190-18

\section{Skróty nazw miejscowości}

AB Abramiki; BU Burchaty; JA Jarmarkowszczyzna; KR Krupki; MA Majorowizna; ME Melechy; NE Nełchy; ON Onacki; OT Otapy; PA Pace; PU Puchacze; SO Solniki; TO Torule; WI Wilginie; WO Wojtki; WY Wysockie; ŻE Żegunie 


\section{Bibliografia}

Abramowicz Zofia, Citko Lilia, Dacewicz Leonarda, Stownik historycznych nazw osobowych Białostocczyzny $(X V-X V I I$ w.), t. 1-2, Białystok: Instytut Filologii Wschodniosłowiańskiej Uniwersytetu w Białymstoku, 1997-1998.

Abramowicz Zofia, Antroponimia Brańska w XVII wieku w kontekście ksztattowania się nazwiska na Podlasiu, [w:] Metodologia badań onomastycznych, Olsztyn: Ośrodek Badań Naukowych im. Wojciecha Kętrzyńskiego, 2003, s. 139-149.

Baranowski Bohdan, Polskie mtynarstwo, Wrocław: Zakład Narodowy im. Ossolińskich, 1977.

Dacewicz Leonarda, Nazewnictwo kobiet $w$ starostwie brańskim, „Białostocczyzna”, t. 4, 1994, s. 69-71, Białostockie Towarzystwo Naukowe, Towarzystwo Przyjaciół Brańska.

Dacewicz Leonarda, Historia nazwisk na kresach pólnocno-wschodnich Rzeczpospolitej (XVI-XVIII w.), Białystok: Wydawnictwo Uniwersytetu w Białymstoku, 2014.

Górny Halszka, O strukturach proprialnych i procesach nazwotwórczych - od ujęć dawniejszych po najnowsze teorie, „Onomastica”, R. 58, 2014, Zakład Narodowy im. Ossolińskich, s. 89-103.

Sajewicz Michal, O polsko-ukraińskiej granicy językowej na Białostocczyźnie, „Rozprawy Slawistyczne", t. 12, red. Feliks Czyżewski, Michał Łesiów, Lublin: Wydawnictwo Uniwersytetu Marii Curie-Skłodowskiej, 1997, s. 91-107.

Sajewicz Michał, Nazwiska patronimiczne z formantem -uk w powiecie hajnowskim na Białostocczyźnie na tle ogólnopolskim, Lublin: Wydawnictwo Uniwersytetu Marii Curie-Skłodowskiej, 2013.

Tichoniuk Bazyli, Imiennictwo osobowe Brańska w XVI wieku, [w:] Nazwy własne a wyrazy pospolite w języku i tekście, Opole: Wyższa Szkoła Pedagogiczna im. Powstańców Sląskich, 1986, s. 235-238.

Tichoniuk Bazyli, Antroponimia południowej Białostocczyzny, Opole: Wyższa Szkoła Pedagogiczna im. Powstańców Sląskich, 1988.

Tichoniuk Bazyli, Imiona i ich formy na pograniczu polsko-białoruskim od XVI wieku do roku 1839, Zielona Góra: Wydawnictwo Wyższej Szkoły Pedagogicznej im. Tadeusza Kotarbińskiego, 2000.

Wiśniewski Jerzy, Osadnictwo wschodniej Białostocczyzny - geneza, rozwój oraz zróżnicowanie i przemiany etniczne, „Acta-Baltico-Slavica”, R. 11, 1977, s. 7-80, Zakład Narodowy im. Ossolińskich.

Zlotkowski Piotr, O pochodzeniu nazwy uroczyska Kumat pod Brańskiem. Czyżby koniec legendy?, „Studia Białorutenistyczne”, t. 8, red. M. Korzeniowski, S.Kawalou, M. Sajewicz, Lublin: Wydawnictwo Uniwersytetu Marii Curie-Skłodowskiej, 2014, s. 237-250.

Zlotkowski Piotr, Strukturno-semanticzeskij analiz polsko-wostocznosławianskich gibridnych familij żtielej Branskogo starostva w XVI-XVIII ww., [w:] Onomastika Povolżja, Moskwa: Instytut Etnologii i Antropologii RAN, 2001, s. 80-86. 
Nazwiska, przezwiska i przydomki młynarzy i mieszkańców osad młyńskich...

\title{
Streszczenie
}

W niniejszym artykule poddano analizie semantyczno-strukturalnej antroponimy (nazwiska, przezwiska, przydomki) młynarzy i mieszkańców osad młyńskich dawnego starostwa brańskiego na Podlasiu w XVI-XIX wieku. Przedmiotem zainteresowania autora jest również proces kształtowania się i stabilizacji nazwisk badanej grupy zawodowej. Uzupełnieniem tekstu jest słownik antroponimów, oparty na wyekscerpowanym materiale źródłowym, w którym ukazano chronologię nazw osobowych oraz ich lokalizację.

Słowa kluczowe: antroponimia, młynarze, nazwy osobowe, Podlasie, starostwo brańskie

\begin{abstract}
Summary
The paper presents semantic and structural analysis of the anthroponyms of millers and inhabitants of mill villages of the Brańsk starosty in the Podlasie region in the 16th-19th centuries. The author also investigates the formation and stabilization of the personal names within this professional group. The text is complemented by dictionary of anthroponyms, based on archival materials containig a chronology of names and their location.
\end{abstract}

Key words: anthroponymy, Brańsk starosty, millers, personal names, Podlasie region 